$5 \quad$ Fares Saïdi ${ }^{1,2 \dagger}$, Utkarsha Mahanta ${ }^{3 \dagger}$, Adyasha Panda ${ }^{3}$, Nicolas Y. Jolivet ${ }^{1,2}$, Razieh Bitazar ${ }^{1,2}$, Gavin 6 John $^{4}$, Matthew Martinez ${ }^{5}$, Abdelkader Mellouk ${ }^{1,2}$, Charles Calmettes ${ }^{1,2}$, Yi-Wei Chang ${ }^{5}$, Gaurav

\title{
Bacterial outer-membrane polysaccharide export (OPX) proteins occupy three structural classes with selective $\beta$-barrel porin requirements for polymer secretion
}

$8 \quad{ }^{1}$ Institut National de la Recherche Scientifique (INRS), Centre Armand-Frappier Santé

9 Biotechnologie, Université du Québec, Institut Pasteur International Network, Laval, QC, Canada

$10{ }^{2}$ PROTEO, the Quebec Network for Research on Protein Function, Engineering, and Applications,

11 Université Laval, Québec, QC, Canadas

$12{ }^{3}$ Institute of Bioinformatics and Applied Biotechnology (IBAB), Bengaluru, Karnataka, India

$13{ }^{4}$ Department of Pediatrics, Division of Infectious Diseases, Children's Hospital of Philadelphia, 14 Philadelphia, PA, U.S.A.

$15{ }^{5}$ Department of Biochemistry and Biophysics, Perelman School of Medicine, University of

16 Pennsylvania, Philadelphia, PA, U.S.A.

$17 \dagger^{\dagger} \mathrm{co}-1^{\mathrm{st}}$ authors

18

$19 *$ corresponding authors:

Salim T. Islam

salim.islam@inrs.ca

ORCID ID: 0000-0001-6853-8446
Gaurav Sharma

gauravsharma@ibab.ac.in

ORCID ID: 0000-0002-2861-7446 


\section{ABSTRACT}

Secretion of high-molecular-weight polysaccharides across the bacterial envelope is ubiquitous as it enhances prokaryotic survival in (a)biotic settings. Such polymers are often assembled by Wzx/Wzy- or ABC transporter-dependent schemes that implicate outer-membrane $(\mathrm{OM})$ polysaccharide export (OPX) proteins in polymer translocation to the cell surface. In the social predatory bacterium Myxococcus xanthus, exopolysaccharide (EPS)-pathway WzaX, major spore coat (MASC)-pathway WzaS, and biosurfactant polysaccharide-pathway WzaB were herein found to be truncated OPX homologues of Escherichia coli Wza lacking OM-spanning $\alpha$-helices.

32 Comparative genomics across all bacteria, complemented with cryo-electron tomography cell-

33 envelope analyses, revealed WzaX/S/B architecture to be the most common amongst three defined

34 OPX-protein structural classes independent of periplasmic thickness. Fold-recognition and deep-

35 learning analyses revealed the conserved M. xanthus proteins MXAN_7418/3226/1916 (encoded

36 adjacent to $\mathrm{WzaX} / \mathrm{S} / \mathrm{B})$ to be integral OM $\beta$-barrels, with structural homology to the poly- $N$-acetyl-D-

37 glucosamine synthase-dependent pathway porin PgaA. Such porins were identified in bacteria near

38 numerous genes for all three OPX-protein classes. Interior MXAN_7418/3226/1916 $\beta$-barrel

39 electrostatics were found to match known properties of their associated polymers. With

40 MXAN_3226 essential for MASC export, and MXAN_7418 absence shown herein to compromise

41 EPS translocation, these data support a novel secretion paradigm for Wzx/Wzy-dependent pathways

42 in which those containing an OPX component that cannot span the OM instead utilize a $\beta$-barrel

43 porin to mediate polysaccharide transport across the OM. 


\section{INTRODUCTION}

Diverse bacteria associated with biotic and abiotic settings secrete high-molecular-weight (HMW) polysaccharides across the cell envelope to enhance their survival. Capsule polysaccharide (CPS) chains are tightly bound to the cell surface and form hydrated exclusionary barriers to molecule entry, whereas exopolysaccharide (EPS) polymers form a more loosely surface-associated glycocalyx around cells that contributes to biofilm matrix formation in aggregates (Whitfield et al., 2020). Certain HMW polysaccharides do not remain associated with the cell surface and are instead secreted to the extracellular milieu where they can influence bacterial physiology (Saïdi et al., 2021, Islam et al., 2020). In both monoderm (Gram-positive) and diderm (Gram-negative) bacteria, multiple secreted polymers often act in concert to modulate complex physiology (Pérez-Burgos \& Søgaard-Andersen, 2020, Lavelle et al., 2021, Franklin et al., 2011). multicellular lifestyle (Muñoz-Dorado et al., 2016). This motile soil bacterium (Faure et al., 2016, Islam \& Mignot, 2015) is able to predate other bacteria (Seef et al., 2021) and saprophytically feed on the degradation products. Under nutrient deprivation, cells in a swarm biofilm form myxosporefilled fruiting bodies through a developmental program resulting in a differentiated cell community (Muñoz-Dorado et al., 2016). This complex lifecycle is modulated by the secretion of three known polysaccharides (Pérez-Burgos \& Søgaard-Andersen, 2020). Cells constitutively produce EPS, a specific surface-associated polymer that forms a glycocalyx surrounding the cell body (Saïdi et al., 2021) and which constitutes the main matrix component in biofilms of this bacterium (Hu et al., 2013, Smaldone et al., 2014). A biosurfactant polysaccharide (BPS) is also synthesized, but is instead secreted to the extracellular milieu (Islam et al., 2020), where it functionally destabilizes the EPS glycocalyx, leading to a range of fundamental behavioural and surface-property changes at the single-cell level (Saïdi et al., 2021). The synergy between EPS and BPS secretion as well as the spatiospecific production patterns of the two polymers (Islam et al., 2020) also impacts the internal architecture of $M$. xanthus swarm biofilms, as well as their Type IV pilus (T4P)-dependent expansion due to impacts on T4P production, stability, and positioning (Saïdi et al., 2021). Finally, the major spore coat (MASC) polymer is produced by spore-forming cells undergoing development, providing a protective coat to cover nascent myxospores and provide resistance to environmental stresses 
Each $M$. xanthus polysaccharide is produced by a separate Wzx/Wzy-dependent assembly

pathway (Islam et al., 2020, Pérez-Burgos et al., 2020, Holkenbrink et al., 2014), the components for

which have the suffixes X (exopolysaccharide), B (biosurfactant), or S (spore coat). Therein, cluster-

specific glycosyltransferases synthesize polymer repeat units atop an undecaprenyl pyrophosphate

(UndPP) lipid anchor at the cytoplasmic leaflet of the inner membrane (IM). UndPP-linked repeats

are then translocated across the IM via the Wzx flippase (Islam et al., 2012, Islam et al., 2013a, Islam

et al., 2010), followed by polymerization at the periplasmic leaflet of the IM by Wzy (Islam et al.,

2011, Islam et al., 2013b) to modal lengths governed by the Wzc polysaccharide co-polymerase

(PCP) in non-O-antigen systems (Fig. 1A) (Islam \& Lam, 2014, Whitfield et al., 2020). In M.

xanthus, WzcB possesses an integrated cytosolic bacterial tyrosine autokinase (BYK) domain (PCP-

2A class), whereas WzcX and WzcS do not (PCP-2B class); the EPS and MASC pathways thus encode a separate BYK (Wze) for association with the cognate PCP (Islam et al., 2020). The Wzb bacterial tyrosine phosphatase (BYP) protein in turn regulates the state of PCP-2A Wzc and PCP-2Bassociated Wze phosphorylation (Mori et al., 2012). Wzb-mediated dephosphorylation of BYK domains has been proposed to drive Wzc octamerization, in turn affecting Wzy-mediated polymerization and interaction with the outer-membrane polysaccharide export (OPX) Wza translocon needed for polymer transport through the periplasm and across the outer membrane (OM) (Yang et al., 2021) (Fig. 1A). Such pathways are one of the most widespread bacterial assembly schemes for HMW polysaccharides, responsible for synthesizing diverse products such as Group 1 CPS and Group 4 CPS (i.e. "O antigen” capsule) as well as colanic acid polymers in enterobacteria (Sande \& Whitfield, 2021), in addition to holdfast polysaccharide in Caulobacter crescentus, (Toh et al., 2008), and xanthan in Xanthomonas campestris (Becker, 2015). In Group 1 CPS systems, the 18stranded integral OM $\beta$-barrel Wzi (internally occluded by an $\alpha$-helical plug domain) is also important as it displays lectin-like characteristics implicated in capsule structure organization

98 (Bushell et al., 2013).

Secreted polymers can also be synthesized by an ABC transporter-dependent scheme in which UndPP-linked polymers are built by sugar unit addition at the cytoplasmic leaflet of the IM,

101 with the polymer generated entirely in the cytoplasm. Subsequent ATP hydrolysis by the transporter 102 drives polymer transport across the IM, after which PCP and OPX proteins are needed for the 103 secretion of polymer through the periplasm and across the OM. These biosynthesis pathways are 104 implicated in the secretion of polysialic acid Group 2 CPS polymers from pathogenic extraintestinal 
E. coli, as well as similar structures in Neisseria meningitidis and Haemophilus influenza (Willis \& Whitfield, 2013).

Alternatively, HMW polymers such as alginate in Pseudomonas aeruginosa, cellulose in Salmonella enterica, and poly- $N$-acetyl-D-glucosamine (PNAG) in Acinetobacter baumanii are produced via a synthase-dependent scheme in which the addition of a monosaccharide in the

110 cytoplasm by an integral IM synthase results in export of the polymer by a similar amount from the 111 cell surface. Polymer transport through the periplasm is mediated by a protein scaffold containing

112 TPR repeats followed by translocation across the OM through an integral OM $\beta$-barrel porin structure 113 (Whitney \& Howell, 2013). While similarities exist between Wzx/Wzy- and ABC transporter114 dependent pathways (e.g. the presence of PCP and OPX proteins), no such schematic crossover with 115 proteins from synthase-dependent pathways has been identified.

In both Wzx/Wzy- and ABC transporter-dependent pathways, OPX-family proteins are 117 portrayed as forming an oligomeric channel of contiguous domains to allow polymer secretion 118 through the periplasm and across the OM (Whitfield et al., 2020). All OPX proteins share a 119 conserved periplasmic N-terminal Poly_export domain (Pfam: PF02563, also called a PES

120 [polysaccharide export sequence] motif), followed by at least one copy of a soluble ligand-binding $\beta$ 121 grasp (SLBB) domain (Pfam: PF10531) (Sande et al., 2019, Cuthbertson et al., 2009), which is

122 predicted to interact with the sugar polymer in the periplasm (Burroughs et al., 2007). OPX protein 123 domain architecture diverges at this point. In the prototypic OPX Wza from E. coli group 1 CPS $124\left(\mathrm{Wza}_{E c}\right)$ — which is the only OPX protein with a solved 3D structure — after one Poly_export (D1) 125 and two SLBB domains (D2 \& D3), the protein contains a Wza_C domain (Pfam: PF18412) at its C126 terminus, which forms a 35-residue amphipathic $\alpha$-helical tract (D4) that crosses the OM (Dong et 127 al., 2006) (Fig. 1A). Elucidation of the WzaEc X-ray crystal structure (PDB: 2J58) was

128 revolutionary as it represented the first instance of such a fold in an integral OM protein. As part of 129 the $\mathrm{Wza}_{E c}$ oligomer, 8 copies of the $\alpha$-helical Wza_C domain were shown to form a pore-like 130 structure, through which it is proposed that secreted polysaccharides exit the cell (Dong et al., 2006, 131 Nickerson et al., 2014) (Fig. 1A). Instead of a classical Wza_C domain, OPX proteins from ABC 132 transporter-dependent Group 2 CPS pathways usually contain a C-terminal Caps_synth_GfcC (Pfam: 133 PF06251, formerly DUF1017) module (Cuthbertson et al., 2009), structurally similar to the stand134 alone GfcC protein (PDB: 3P42) from Group 4 Wzx/Wzy-dependent CPS pathways (Sande et al., 135 2019). GfcC contains domains comparable to D2 and D3 from Wza $\mathrm{E}_{E c}$, as well as a D4-like 
136 amphipathic $\alpha$-helix; however, the GfcC D4-like helix spanning the final 21 residues of the protein is

$13740 \%$ shorter than $\mathrm{Wza}_{E c} \mathrm{D} 4$, bent at both ends, and structurally locked (Sathiyamoorthy et al., 2011).

138 This overall OPX architecture is typified by the Group 2 CPS pathway protein KpsD from E. coli

$139\left(\mathrm{KpsD}_{E c}\right)$ (Sande et al., 2019). Though it is uncertain if the C-terminal domain of $\mathrm{KpsD}_{E c}$ is able to

140 span the $\mathrm{OM}, \mathrm{KpsD}_{E c}$ epitopes have previously been detected at the cell surface via anti-KpsD $\mathrm{K}_{E}$

141 antibody labelling (McNulty et al., 2006). Numerous other annotated OPX proteins have been shown

142 to either (i) contain considerable-yet-uncharacterized protein sequences following their most C-

143 terminal identified domain, or (ii) be considerably shorter than either $\mathrm{Wza}_{E c}$ or $\mathrm{KpsD}_{E c}$, with

144 architecture beyond the Poly_export and SLBB domains largely absent (Cuthbertson et al., 2009).

145 Ultimately, for OPX proteins that lack a canonical OM-spanning Wza_C domain, the manner by

146 which the respective secreted polymers traverse the asymmetric OM bilayer remains a fundamental

147 and pertinent question that has yet to be resolved.

148 Herein, we reveal that the WzaX, WzaB, and WzaS OPX proteins for the respective $M$.

149 xanthus EPS, BPS, and MASC pathways contain typical N-terminal "Poly_export-SLBB"

150 architecture but lack a C-terminal OM-spanning Wza_C domain. Comparative genomics analyses

151 reveal this architecture to be the most common amongst three distinct structural classes of OPX

152 proteins across all bacteria. However, in the M. xanthus EPS, BPS, and MASC biosynthetic clusters,

153 a conserved $\beta$-barrel protein (MXAN_7418/MXAN_1916/MXAN_3226) is encoded immediately

154 adjacent to the genes for $\mathrm{WzaX} / \mathrm{WzaB} / \mathrm{WzaS}$ (respectively). Fold-recognition and deep-learning

155 analyses reveal these adjacently-encoded proteins to be 18-stranded integral OM $\beta$-barrels with

156 structural homology to the barrel domain of the porin PgaA, required for PNAG secretion across the

157 OM by synthase-dependent pathways. In turn, PgaA-like $\beta$-barrel proteins are shown to be encoded

158 near numerous genes representing all three OPX structural classes in diverse Gram-negative bacteria.

159 The interior electrostatics of the $M$. xanthus $\beta$-barrels match known properties of their associated

160 polymers, and deletion of the MXAN_7418 $\beta$-barrel is shown to compromise EPS secretion.

161 Together with the known requirement for the MXAN_3226 $\beta$-barrel for MASC secretion

162 (Holkenbrink et al., 2014), these data support a novel secretion paradigm for Wzx/Wzy-dependent

163 pathways in which those containing an OPX component that cannot span the OM instead utilize a $\beta$ -

164 barrel porin to mediate translocation of HMW polymers across the OM. 
165 Figure 1. Wzx/Wzy-dependent polysaccharide assembly-and-secretion. A) Pathway schematic.

166 Inset: The Wza $\mathrm{E}_{C}$ X-ray crystal structure octamer (PDB: 2J58) has been differentially coloured to

167 highlight the position of each chain in the structure. The D1 (Poly_export), D2 \& D3 (both SLBB), and

168 D4 (Wza_C) domains have been indicated, with smooth loops. B) Tertiary structure models of $M$.

169 xanthus EPS-pathway WzaX (aa 51-212), MASC-pathway WzaS (aa 32-190), and BPS-pathway

170 WzaB (aa 38-202) based on the Wza $E_{E c}$ structure (aa 22-376, depicted with a N-terminal lipid anchor).

171 Structures are displayed with smooth loops, highlighted $\beta$-sheets (yellow) and $\alpha$-helices (red), with the

172 various $\mathrm{N}$ - and $\mathrm{C}$ - termini indicated. 
bioRxivpreprintdoi: https://doi.org/10.1101/2022.02.11.480155; this version posted February 12,2022 . The copyright holder for this preprint - G(which was not certified by peer review) is the author/funder, who has granted bioRxiv a license to display the preprint in perpetuity. It is made

A)
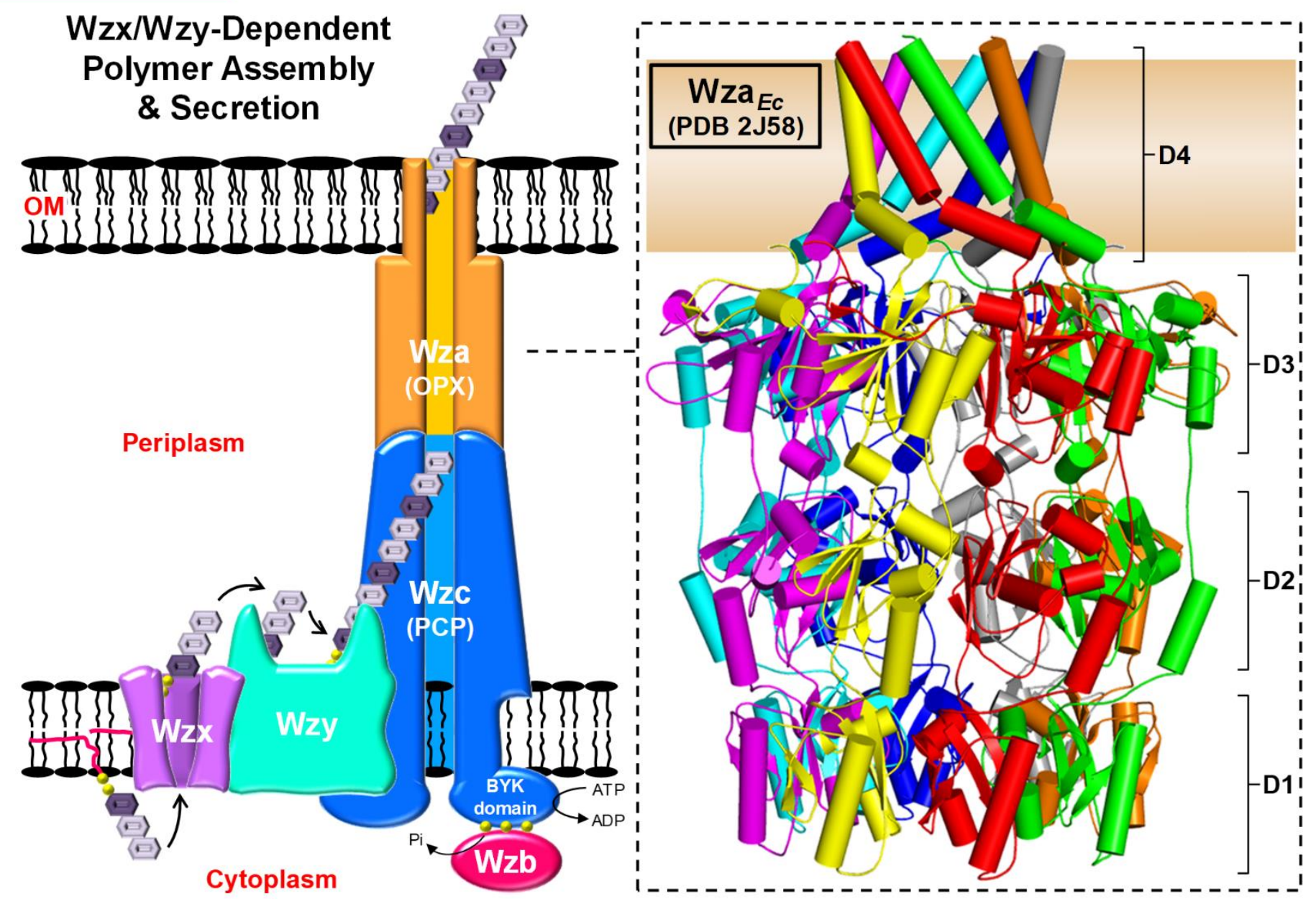

B)

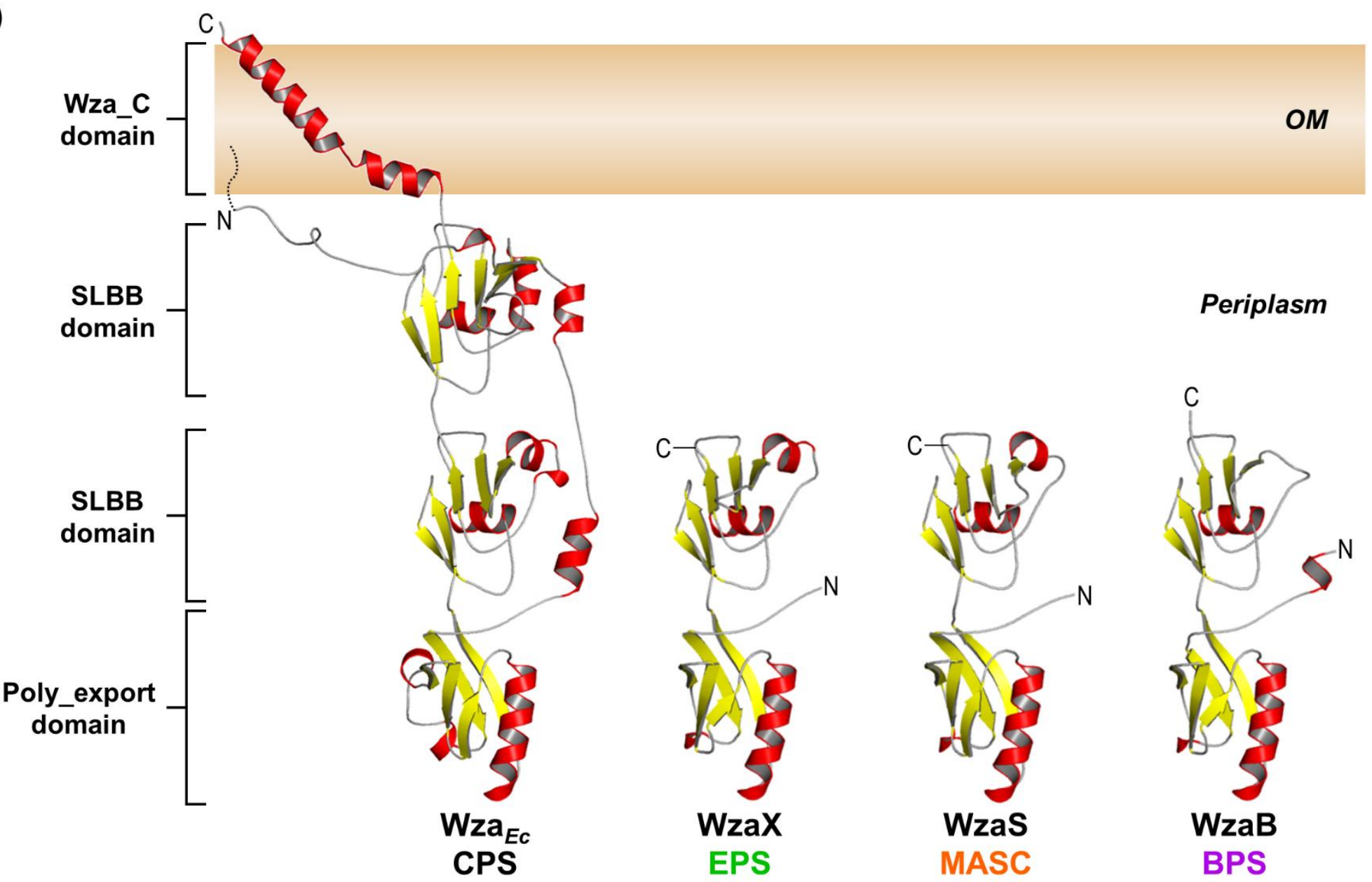

(PDB: 2J58) 


\section{RESULTS}

175 The M. xanthus OPX proteins WzaX, WzaS, and WzaB lack an OM-spanning a-helix domain

176 Each of the WzaX/S/B OPX proteins is essential for the secretion of its respective

177 EPS/MASC/BPS polymer in M. xanthus (Islam et al., 2020, Holkenbrink et al., 2014). However, as

178 each of WzaX, WzaS, and WzaB has a considerably shorter amino acid sequence than that of Wza $E c$

179 (44, 50, and 46\% smaller, respectively), we sought to better understand the structural implications of

180 this difference. Fold-recognition analysis of each protein revealed 100\%, 100\%, and 99.9\%

181 probability matches (respectively) to the N-terminal half of the high-resolution Wza ${ }_{E c}$ X-ray crystal

182 structure. However, tertiary structure modelling of WzaX, WzaS, and WzaB against the Wza $E c$ 3D

183 structure revealed WzaX, WzaS, and WzaB to be missing the $2^{\text {nd }}$ SLBB domain (i.e. D3), and more

184 importantly the crucial OM-spanning $\alpha$-helical Wza_C domain (i.e. D4), of WzaEc (Fig. 1B). The

185 absence of such an OM-spanning domain is consistent with the lack of WzaX/S/B detection in

186 proteomic analyses of OM vesicle (OMV) and biotinylated surface-protein samples (Kahnt et al.,

187 2010), despite the constitutive expression of the $w z a X / S / B$ genes throughout the $M$. xanthus lifecycle

188 (Muñoz-Dorado et al., 2019, Sharma et al., 2021). 
189 Figure 2. Structural diversity of OPX proteins. A) Domain organization and abundance of

190 bacterial OPX protein classes identified in the myxobacterial (MYXO, 61 genomes, 506873 proteins

191 analyzed), representative (REP, 3662 genomes, 13600490 proteins analyzed), and NCBI non-

192 redundant (NR, 371327556 proteins analyzed) databases. The Poly_export (PF02563), SLBB

193 (PF10531), Wza_C (PF18412), and Caps_synth_GfcC (PF06251) Pfam domains were used to

194 query the various databases, followed by fold-recognition analysis using HHpred against the 3D X-

195 ray crystal structures of $\mathrm{Wza}_{E C}$ (PDB: 2J58) and GfCC (PDB: 3P42). The number of repeated copies

196 is indicated under each domain depiction. The number of OPX hits (bold) for a specific class is

197 indicated as well as the proportion of hits from each database (italics) represented by the hits.

198 Sequence logo of the consensus amino acids constituting the OM-spanning $\alpha$-helix based on a

199 multiple-sequence alignment of 1586 Class 1 OPX proteins. The region of sequence alignment

200 with $\mathrm{Wza}_{E c}$ is indicated and depicted with the associated secondary structure from the Wza $\mathrm{E}_{E} \mathrm{X}$-ray

201 crystal structure (PDB: 2J58) (Dong et al., 2006). Also depicted is the region of sequence alignment

202 with a previously-published optimized Wza_C synthetic peptide (based on 94 close Wza ${ }_{E C}$-related

203 homologues) capable of spontaneously inserting into lipid bilayers and self-assembling into stable $\alpha$ -

204 barrel pores (Mahendran et al., 2017). C) Sequence logo of the consensus amino acids

205 constituting the putative OM-spanning a-helix based on a multiple-sequence alignment of 452 Class

206 2B OPX proteins. The region of sequence alignment with $\mathrm{Kps}_{E c}$ is indicated, along with the

207 predicted $\mathrm{KpsD}_{E c}$ secondary structure. The position of observed (dark-colored) and predicted (light-

208 colored) $\alpha$-helices (boxes) and $\beta$-strands (arrows) have been indicated. 
bioRxiv preprint doi: https://doi.org/10.1101/2022.02.11.480155; this version posted February 12,2022 . The copyright holder for this preprint (which was not certified by peer review) is the author/funder, who has granted bioRxiv a license to display the preprint in perpetuity. It is made available under aCC-BY-NC 4.0 International license.

\section{FIGURE 2}

A)

\begin{tabular}{|c|c|c|c|c|}
\hline \multirow[t]{3}{*}{ Databases: } & MYXO & REP & NR & \\
\hline & 61 & 3662 & All & Total Genomes Analyzed \\
\hline & 506873 & 13600490 & 371327556 & Total Proteins Analyzed \\
\hline
\end{tabular}

OPX Class Database Search Results $\quad$ OPX Protein Architecture

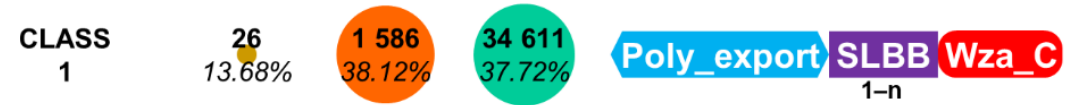

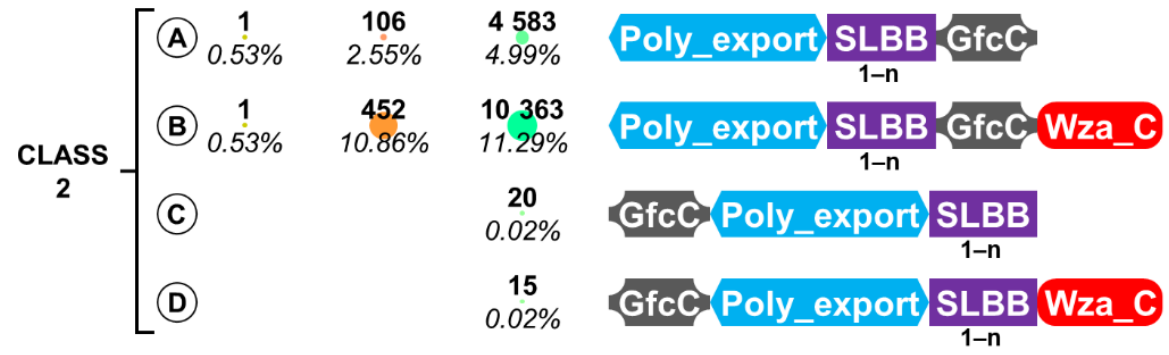

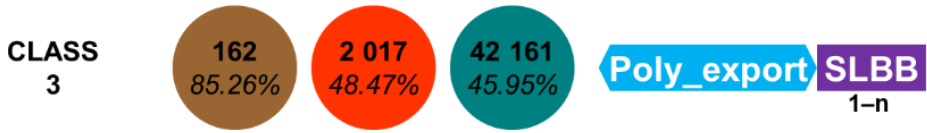

$190 \quad 4161 \quad 91753 \quad$ Total Identified OPX Proteins

B)

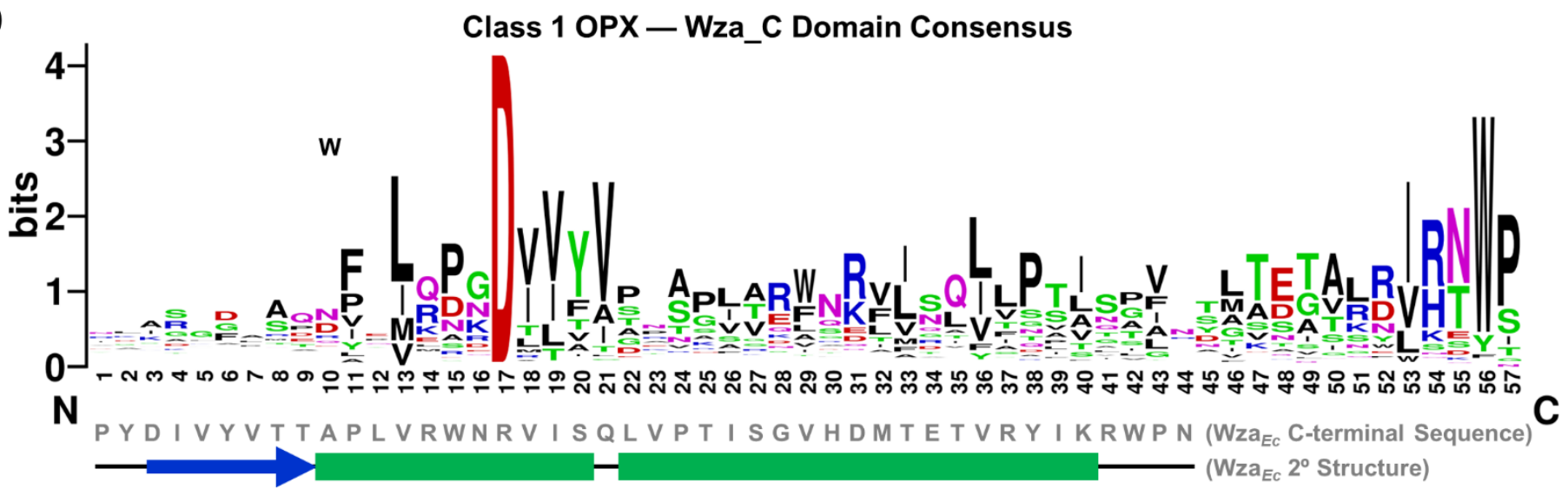

A P L V R W N R I S L V P T I T G V H L T E T V R Y I K T W N (Self-Inserting Consensus Wza Peptide)

C) Class 2B OPX - Wza_C Domain Consensus

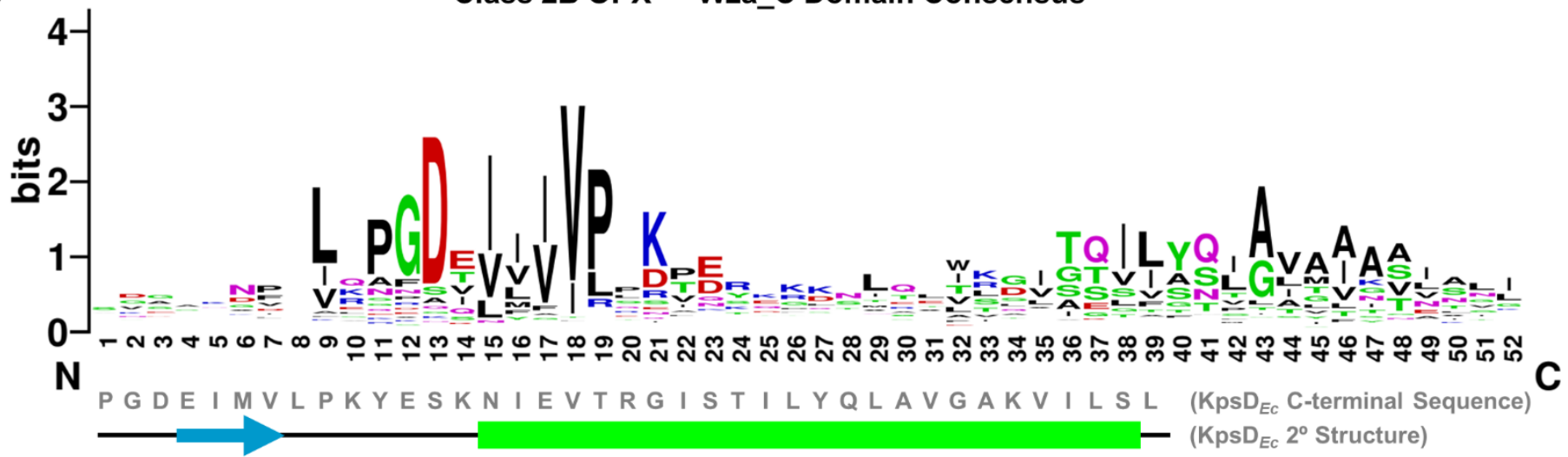




\section{OPX proteins constitute three distinct structural classes}

To determine if the absence of the Wza_C domain was an aberration confined to the subset of

212 OPX proteins from $M$. xanthus under study, we first performed a comparative genomics analysis

213 using profile-based homology searches across three different datasets: (i) 61 myxobacterial genomes

214 (MYXO) (Supplementary Table S1), (ii) 3662 representative genomes (REP) (Supplementary

215 Table S2), and (iii) the non-redundant (NR) NCBI database (371 327556 proteins at 100\% identity

216 as of June 10, 2021) (Supplementary Table S3), to identify encoded OPX proteins, using

217 PF02563 [Poly_export], PF10531 [SLBB], PF18412 [Wza_C], and PF06251 [Caps_synth_GfcC;

218 used here as "GfcC"] as our query domains. These profile-based analyses identified diverse putative

219 OPX homologues that we divided into three distinct classes according to their domain architecture

220 (Fig. 2A). The first set of OPX proteins was found to contain Poly_export-SLBB $(1-14)$ architecture

221 ending with a C-terminal OM-spanning Wza_C domain, similar to Wza $\mathrm{E}_{E c}$, and was assigned the

222 designation "Class 1" (Fig. 2A). A second set of OPX proteins was found to possess Poly_export-

$223 \operatorname{SLBB}_{(1-6)}-\mathrm{GfcC}$ architecture similar to $\mathrm{KpsD}_{E c}$, ending with or without a C-terminal OM-spanning

224 Wza_C domain, and was assigned the designation “Class 2". However, most OPX proteins were

225 found to contain only Poly_export-SLBB $(1-7)$ architecture lacking either a Wza_C or GfcC domain;

226 these hits were designated "Class 3"; however, many of these initial hits were found to contain

227 additional amino acids that may have remained uncharacterized following sequence-based domain

228 detection. Therefore, to probe these partially-characterized hits in more detail, we subjected all

229 identified OPX proteins to fold-recognition analysis using HHpred to identify matches with more

230 remote sequence homology but conserved structural properties. These analyses resulted in

231 reclassification of several original Class 3 hits to either Class 1 or Class 2

Incidentally for Class-1 OPX proteins, while the secondary structure was conserved,

233 considerable sequence variation was detected within certain regions of the putative OM-spanning

234 Wza_C domains, with this domain extending up to 48 residues in length (compared to 35 residues in

$\left.235 \mathrm{Wza}_{E c}\right)$ (Fig. 2B). As per the MYXO/REP/NR databases, 13.7/38.1/37.7\% of OPX proteins possess

236 Class $1 \mathrm{Wza}_{E c}$-like organization with a putative OM-spanning C-terminal $\alpha$-helix (Fig. 2A,

237 Supplementary Tables S1, S2, S3). Class 1 OPX proteins were found to have a median length

238 of 378 amino acids and most $(1233 / 1586, \sim 78 \%)$ were predicted to be lipoproteins with Sec/SPII

239 signal sequences. 
These proteins were largely confined to the phylum Proteobacteria (837/1632 genomes; $\sim 51 \%$ ) with a predominance in classes Gammaproteobacteria (430/760 genomes; 56\%), Alphaproteobacteria (232/410 genomes; 57\%), and Betaproteobacteria (133/274 genomes; 49\%), and representation also in phyla Bacteroidetes (67/283 genomes; 24\%), Planctomycetes (56/62 genomes; 90\%), and Cyanobacteria (46/55 genomes; 84\%) (Supplementary Table S2). Based on species-level PSORTdb classification, the REP database contains 698 Gram-positive and 1381 Gram-negative organisms. Our analysis revealed that Class 1 OPX proteins are encoded by many Gram-negative bacteria (639/1381 genomes, 46\%), whereas these proteins were completely absent in Gram-positive species (Supplementary Table S2).

Our MYXO/REP/NR database comparative genomic analysis revealed that Class 2 OPX proteins can be further divided into four subclasses. Proteins belonging to Class $2 \mathrm{~A}$ contain $\operatorname{SLBB}_{(1-\mathrm{n})}-\mathrm{GfcC}-\mathrm{Wza} \_\mathrm{C}$ architecture ending with an OM-spanning $\alpha$-helical domain. Classes $2 \mathrm{C}$ by a GfcC domain; however, only 20 Class $2 \mathrm{C}$ and 15 Class 2D proteins were identified across the entire NR database.

Class 2A OPX proteins constitute $0.5 / 2.6 / 5.0 \%$ of all OPX proteins identified in the MYXO/REP/NR databases, with a median length of 605 amino acids. These proteins were found to be encoded mainly in Proteobacteria (77/1632 genomes, $\sim 5 \%)$, Bacteroidetes (9/283 genomes, 3\%), and Acidobacteria (3/14 genomes, 21\%). Taxonomy orders Alteromonadales (14/83 genomes, 17\%), Campylobacterales (10/88 genomes, 11\%), Burkholderiales (9/175 genomes, $\sim 5 \%$ ), and Oceanospirillales $(9 / 43$ genomes, $\sim 21 \%)$ display the maximum representation for Class $2 \mathrm{~A}$. In addition, Class 2A OPX proteins are encoded in only 5\% (66/1381 genomes) of Gram-negative bacteria and are completely absent among Gram-positive species (Supplementary Table S4). MYXO/REP/NR databases (Fig. 2A, Supplementary Table S1, S2, S3). The median length of Class 2B proteins was found to be 824 amino acids, with most $(375 / 452, \sim 83 \%)$ found to possess standard Sec/SPI secretory signal peptides. These proteins were largely encoded by Proteobacteria (226/1632 genomes, 14\%), Bacteroidetes (107/283 genomes, $\sim 38 \%)$ and Cyanobacteria (14/55 
(38/52 genomes, 73\%), Cytophagales (23/50 genomes, 46\%), and Vibrionales (20/46 genomes, $\sim 43 \%$ ) were found to contain the most organisms encoding Class 2B OPX architecture. Class 2B OPX proteins have representation in only $~ 18 \%$ (243/1381 genomes) of Gram-negative organisms and are absent in Gram-positive bacteria (Supplementary Table S4).

Class $2 \mathrm{~B}$ architecture is typified by $\mathrm{KpsD}_{E c}$. Consistent with a previous report (Sande et al., 2019), fold-recognition analysis of $\mathrm{KpsD}_{E c}$ revealed that most of its $\mathrm{N}$-terminus is structurally homologous to $\mathrm{Wza}_{E c}$, while the bulk of its C-terminus is a structural match to the standalone GfcC protein (Supplementary Fig. S1A). However, the extreme C-terminus of $\mathrm{KpsD}_{E c}$ - i.e. the portion of $\mathrm{KpsD}_{E c}$ surpassing the end of structural homology with the GfcC D4 $\alpha$-helix — was found to have considerable structural homology with the most C-terminal region of $\mathrm{Wza}_{E c}$, including a 25residue tract with $\alpha$-helical propensity matched to the OM-spanning $\alpha$-helical tract of Wza $E c$

(Supplementary Fig. S1B,C). A similarly-extended C-terminal $\alpha$-helix was found throughout the Class 2B OPX hits identified herein, with considerable variation in certain regions of its sequence, and extending to 38 residues (compared to 25 residues in $\mathrm{KpsD}_{E c}$ ) (Fig. 2C). This observation supports the notion that a part of $\mathrm{KpsD}_{E c}$ (and by extension Class 2B OPX proteins) may indeed be able to span the OM and access the cell surface.

Finally, Class 3 OPX proteins with Poly_export-SLBB $(1-n)$ architecture (but no appreciable peptide sequence following their respective C-terminal-most SLBB domain), with a median length of 256 amino acids, represent a plurality ( 85/49/46\%) of OPX proteins identified across the MYXO/REP/NR databases (Fig. 2A, Supplementary Table S1, S2, S3). Almost 50\% are predicted lipoproteins (Sec/SPII signal sequences) while $\sim 30 \%$ are secreted proteins (Sec/SPI signal sequences). Such OPX proteins (i.e. those lacking a Wza_C or GfcC) domain were found across multiple bacterial classes such as Alphaproteobacteria (274/410 genomes, 67\%),

293 Gammaproteobacteria (247/760 genomes, 33\%), Betaproteobacteria (100/274 genomes, 37\%),

294 Flavobacteria (116/133 genomes, 87\%), and Deltaproteobacteria (66/82 genomes, $\sim 80 \%)$.

295 Expectedly, our analysis detected Class 3 OPX proteins in Gram-negative bacteria (600/1382 genomes, $43 \%$ ), but also intriguingly in several Gram-positive organisms (52/699 genomes, 7\%) (Supplementary Table S4). Of note, the proportions of each Class of OPX protein detected in the REP database were highly reflective of those found in the NR database (Fig. 2A), reinforcing the utility and applicability of the REP database. 
Within the MXYO dataset, we identified 26 Class 1, two Class 2, and 162 Class 3 OPX

301 proteins (Fig. 2A, Supplementary Table S1). Class 3 OPX proteins were encoded in all 61

302 myxobacterial organisms, without any exception, in the range of 1-4 proteins. Class 1 OPX proteins

303 were encoded by several members of the suborder Cystobacterineae such as Anaeromyxobacter,

304 Cystobacter, Corallococcus, Pyridicoccus, and Simulacricoccus. However, Class 1 OPX proteins

305 were not represented within any species of the genus Myxococcus. Class 2 OPX proteins were only

306 present in two myxobacteria, namely Sandaracinus amylolyticus (Class 2A OPX) and Haliangium

307 ochraceum (Class 2B OPX). All proteins in the MYXO dataset belonging to the three OPX classes

308 possess similar median lengths to those described for all OPX proteins in the REP database (i.e.

309 MYXO Class 1, 373 amino acids; MYXO Class 2, 550 amino acids; MYXO Class 3, 205 amino

310 acids). 
311 Figure 3. Phylogenetic tree of OPX proteins. Sequence alignment of all "Poly_export" domains

312 as identified in 4161 OPX proteins in the REP dataset was used to generate a maximum-likelihood

313 phylogenetic tree. The classes of OPX proteins (inner tree) and their respective phyla (outer ring)

314 have been coloured accordingly for effective visualization. 
bioRxivpreprintedoi: https://doi.org/10.1101/2022.02.11.480155; this version posted February 12,2022 . The copyright holder for this preprint G Ghich was mot certified by peer review) is the author/funder, who has granted bioRxiv a license to display the preprint in perpetuity. It is made
available under aCC-BY-NC 4.0 International license.

\section{Colored Ranges (Phylum-Level Taxonomy)}

$\begin{array}{lllll}\square \text { Proteobacteria } & \text { Cyanobacteria } & \text { Verrucomicrobia } & \square \text { Chlamydiae } \\ \square \text { Actinobacteria } & \text { Planctomycetes } & \square \text { Chlorobi } & \square \text { Thermotogae } \\ \square \text { Firmicutes } & \text { Bacteroidetes } & \square \text { Nitrospirae } & \square \text { Acidobacteria }\end{array}$

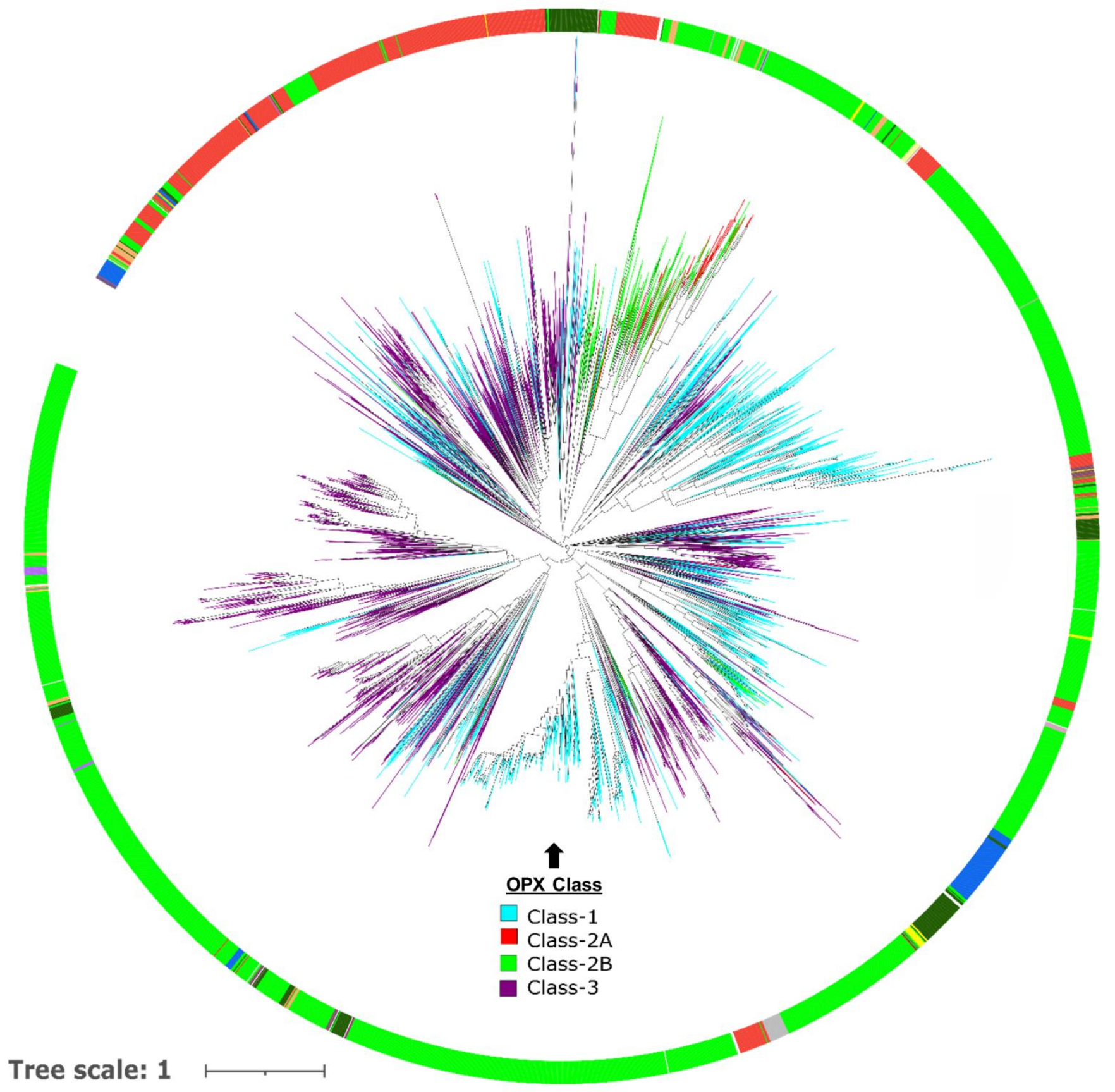


Molecular phylogenetics suggests the coevolution of three OPX protein Classes

Taken together, these analyses have identified three principal structural classes of OPX

318 proteins, namely: (i) Class 1 (i.e. $\mathrm{Wza}_{E c}$-like with a canonical OM-spanning $\alpha$-helix), (ii) Class 2 (i.e.

$319 \mathrm{KpsD}_{E c}$-like with a potentially OM-spanning $\alpha$-helix at the terminus of the GfcC domain), and (iii)

320 the majority Class 3 (i.e. those with structural homology to the Wza $E_{c} \mathrm{~N}$-terminus, but with no

321 discernible OM-spanning domain). By extension, WzaX/S/B from M. xanthus (Fig. 1B) are thus

322 Class 3 OPX proteins that share the domain architecture of most other OPX proteins encoded by

323 bacteria (Fig. 2A). Given that all OPX proteins among the three different classes have a conserved

324 "Poly_export" domain, this can be utilized as a phylogenetic marker. Therefore, based on the

325 hmmscan results, we extracted the location of the "Poly_export" domain from REP dataset hits,

326 aligned those sequences using MUSCLE, and generated a maximum-likelihood phylogeny. The

327 generated phylogeny (Fig. 3) revealed that Class 1 and Class 3 OPX proteins are interspersed with

328 each other in all taxonomic clades, suggesting that proteins from these two classes have co-evolved

329 by losing or gaining the Wza_C segment in closely-related organisms. However, Class 2A and Class

$3302 \mathrm{~B}$ are both present in nearby sister clades and away from Class 1 and Class 3 . This denotes that

331 Class 2 OPX proteins, similar to proteins from Class 1 and Class 3, are highly similar to each other

332 and have coevolved by losing or gaining their respective Wza_C segments. 
333 Figure 4. Cell envelope ultrastructure in Gram-negative bacteria. A) Cryo-electron microscopy

334 tomogram slice of a $M$. xanthus cell, showing the IM, OM, and intervening periplasmic space and

335 their respective measured thicknesses. B) Comparison of means (black bar) for periplasmic

336 distances in 40 microbial species ( \pm SEM). Individual replicate measurements are indicated (red

337 dots). Data from organisms with increasing mean periplasmic thickness values have been depicted

338 from left to right, grouped according to Gram-negative, Gram-positive, or Archaea organism

339 designation. C) Scatterplot of mean periplasmic thickness values plotted against the length of each

340 OPX protein from the same organism. Data points have been coloured according to the Class of

341 OPX protein assigned herein. No correlation was detected between periplasmic thickness and (i)

342 overall OPX protein length (Pearson coefficient: 0.1450; Spearman coefficient: 0.05884, calculated

343 over 92 data pairs), (ii) Class 1 OPX hits (Pearson coefficient: 0.07250; Spearman coefficient:

344 0.2318; calculated over 33 data pairs), or (iii) Class 3 OPX hits (Pearson coefficient: -0.1127;

345 Spearman coefficient: -0.1242 ; calculated over 53 data pairs). 
bioRxiv preprint doi: https://doi.org/10.1101/2022.02 11.480155; this version posted February 12, 2022. The copyright holder for this preprint (which was not certified by peer review) is the author/funder, who has granted bioRxiv a license to display the preprint in perpetuity. It is made

\section{FIGURE 4}

A)

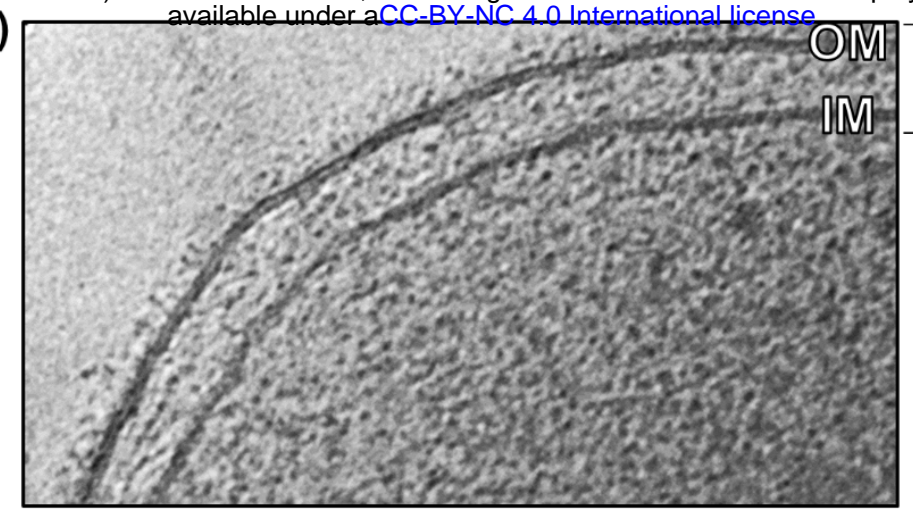

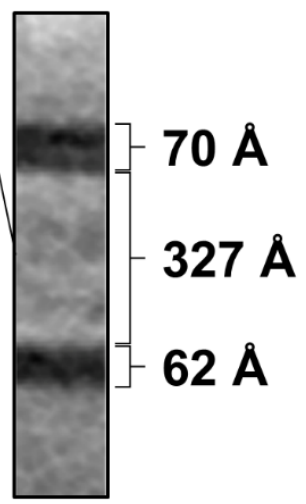

B)

\section{Microorganism Periplasmic Thicknesses}

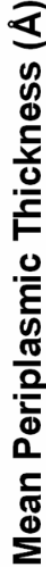

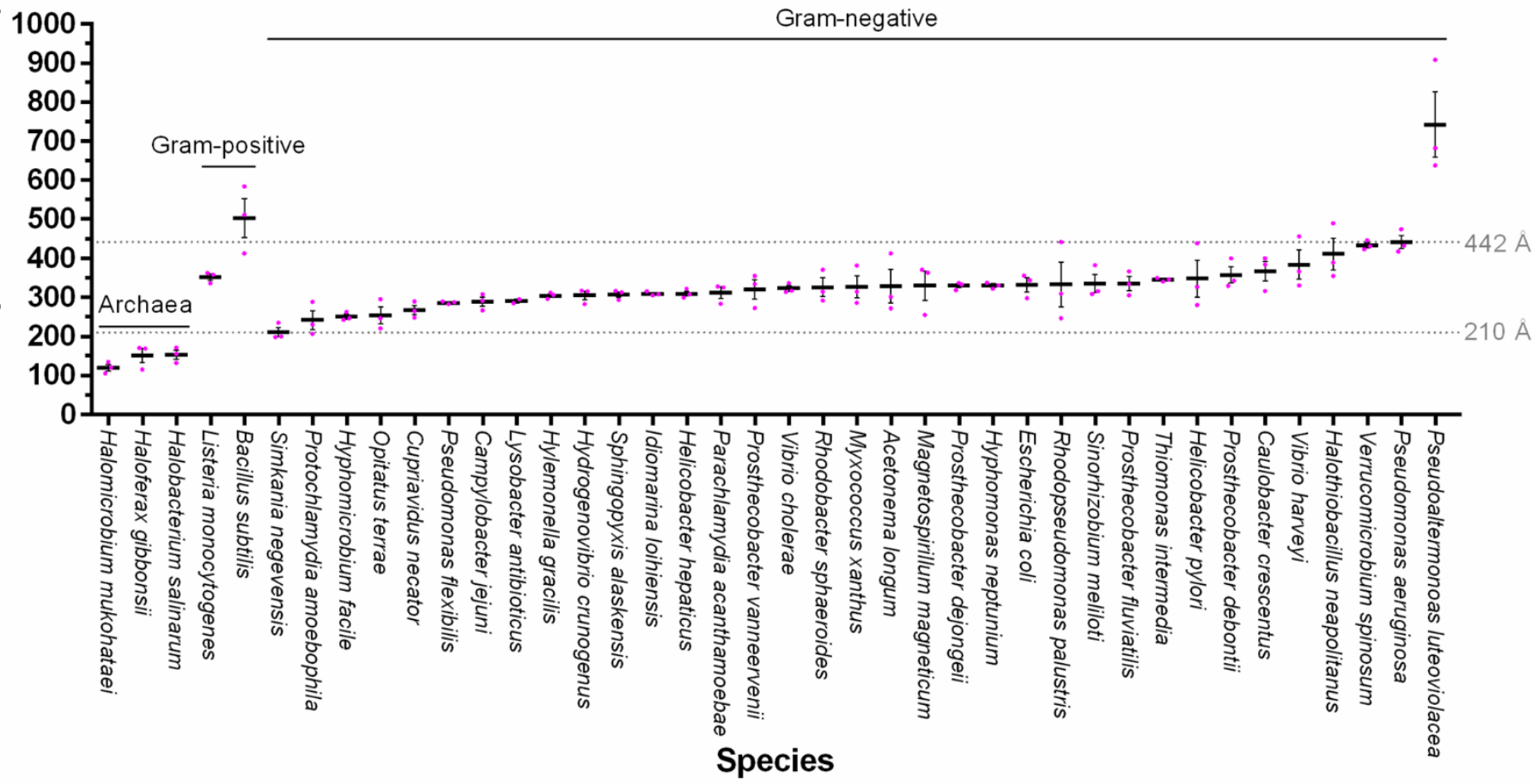

C)

Periplasm vs. OPX Sizes

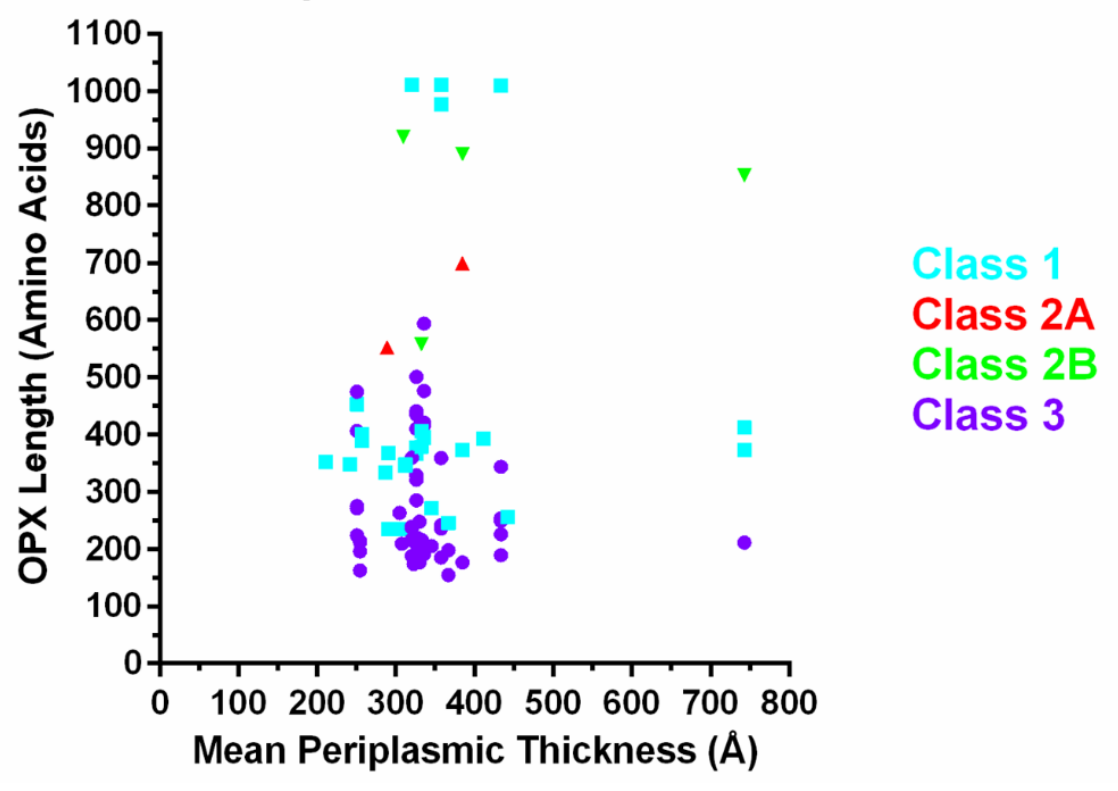


OPX protein lengths and classes in Gram-negative bacteria are not linked to periplasmic distance

In E. coli, the integral OM Class $1 \mathrm{Wza}_{E c}$ OPX protein is proposed to form a complex with the integral IM Wzc PCP protein that creates a contiguous periplasm-spanning channel for polymer export (Collins et al., 2007) (Fig. 1A). To gain an understanding of the relationship between the subcellular architecture of $M$. xanthus and the role of the WzaX, WzaS, and WzaB Class 3 OPX proteins, we therefore compared the sizes of various cellular compartments and structures from cryoelectron tomography projections of the M. xanthus envelope. This revealed the M. xanthus OM to have an average thickness of $69.8 \pm 1.8 \AA$, compared to the average thickness of $62 \pm 1.6 \AA$ for its IM, with a mean inter-membrane periplasmic thickness of $327 \pm 28.4 \AA$ (Fig. 4A).

Given the enrichment of Class 1 OPX proteins in certain bacterial genera and different median OPX sizes for each OPX protein class (Supplementary Table S4), we examined whether the specific size of an OPX protein identified in a given bacterium was associated with the thickness of the periplasm in that organism. We first measured the distance between the IM and OM at lateral positions in cryo-electron tomography projections of cells from an additional 34 species of Gramnegative bacteria. For reference, we also analyzed IM-peptidoglycan and IM-S-layer thickness in several Gram-positive bacteria and Archaea (respectively) (Fig. 4B). This analysis revealed a range of Gram-negative periplasmic thicknesses confined between the lower and upper thresholds of 210 and $442 \AA$ (respectively), with the lone exception being Campylobacter jejuni, displaying a mean periplasmic thickness of $743 \AA$ (Fig. 4B). For any of these species in which OPX proteins were herein identified (Supplementary Tables S1, S2, S3), we next compared the average measured periplasmic thickness with the length of the OPX protein(s) in each system. However, no overall correlation between the two variables was detected across all OPX proteins in this analysis, nor specifically within Class 1 or Class 3 OPX hits (Fig. 4C). 
Given the lack of identifiable OM-spanning domains in WzaX/S/B (Fig. 1B), we sought to identify candidate proteins that could permit export of synthesized EPS, MASC, and BPS polymers across the M. xanthus OM. Through our previous analyses of the EPS, MASC, and BPS biosynthesis clusters, we demonstrated that WzaX (MXAN_7417), WzaS (MXAN_3225), and WzaB (MXAN_1916) were encoded immediately adjacent to MXAN_7418, MXAN_3226, and MXAN_1916 (respectively), with this synteny conserved for the majority $(115 / 162, \sim 71 \%)$ of Class 3 OPX proteins in myxobacterial genomes (Islam et al., 2020), supporting the notion that the latter three proteins are important for each respective polymer synthesis pathway. To analyze the specific structural potential for each protein, MXAN_7418, 3226, and 1916 were first subjected to evolutionary coupling analysis, revealing the predicted presence of 18 principal $\beta$-strands for MXAN_7418, MXAN_3226, and MXAN_1916 (Supplementary Figs. 2A,3A,4A). of PgaA (PgaA $\beta$ b, PDB: 4Y25) (Wang et al., 2016), at 98.9\%, 99.4\%, and 99.2\% probability (respectively). PgaA is the OM porin responsible for secretion of PNAG polymer (which is heavily implicated in biofilm integrity) in Gram-negative bacteria; it contains multiple periplasmic tetratricopeptide repeats at its $\mathrm{N}$-terminus, followed by a 16-stranded integral OM $\beta$-barrel domain closed by four extracellular loops (Wang et al., 2016). Intriguingly, PNAG is produced by a synthase-dependent pathway (Whitney \& Howell, 2013). In each of MXAN_7418/3226/1916, the $\mathrm{PgaA}_{\beta b}$-like module is extended by two integral OM $\beta$-strands at the $\mathrm{N}$-terminus of each protein, suggesting that MXAN_7418, 3226, and 1916 do indeed have the propensity to form 18-stranded $\beta$ barrels (Supplementary Figs. 2B,3B,4B).

For the 162 Class 3 OPX proteins identified across 61 myxobacterial genomes (with

394 Poly_export-SLBB $1-2$ architecture), most $(115 / 162, \sim 71 \%)$ were found to be encoded near an

395 extended PgaA $\beta$ b-like protein, whereas the 26 Class 1 (with Poly_export-SLBB $1-2$-Wza_C organization) and two Class 2 OPX proteins were not encoded near any such $\beta$-barrel protein

397 (Supplementary Table S1). We again expanded our analysis beyond M. xanthus to determine 398 whether the presence of a $\beta$-barrel porin was a common occurrence in pathways containing an OPX protein. Intriguingly in E. coli, the $g f c A B C D E$-etp-etk cluster needed for Wzx/Wzy-dependent Group 
4 CPS production, encodes the OPX protein GfcE (formerly YccZ/Wza $22 \mathrm{~min}$ ) as well as the protein

GfcD (formerly YmcA) (Peleg et al., 2005). The separate yjbEFGH (paralogous to $g f c A B C D$ ) operon implicated in polysaccharide secretion encodes the GfcD-like protein YjbH (Ferrières et al., 2007). Both GfcD and YjbH are $\beta$-barrel proteins, which were recently identified to be part of a novel class of OM proteins (lacking published structures) with two separate $\beta$-barrels predicted to be formed by the same polypeptide chain (Solan et al., 2021). Herein, fold-recognition analysis revealed the $\mathrm{N}$-terminal halves to be matches to the $\beta$-barrel amyloid transporter FapF from Pseudomonas, whereas the C-terminal halves $\left(\mathrm{GfcD}_{\mathrm{Cter} \beta \mathrm{b}}\right.$ and $\mathrm{YjbH}_{\mathrm{Cter} \beta \mathrm{b}}$, respectively) possessed structural homology to the PNAG PgaA ${ }_{\beta b}$ module described above (Supplementary Fig. 5A). This double-barrel arrangement was supported by AlphaFold2-generated deep-learning structure models for both full-length GfcD and YjbH (Supplementary Fig. 5B), with the larger barrel portions displaying considerable sequence homology to $\operatorname{PgaA}_{\beta b}$ (Supplementary Fig. 5C).

To probe for the presence of similar $\beta$-barrels encoded near other OPX proteins, we used 413 sequence homology searches (BLAST and HMMER) to examine the genomic context (up to 10 414 genes upstream and downstream) of the various OPX proteins we identified in the REP dataset, 415 beginning with the $\beta$-barrel sequences of MXAN_7418, MXAN_3226, and MXAN_1916. Given the homology of the above proteins to PgaA, we added the $\mathrm{PgaA}_{\beta \mathrm{b}}, \mathrm{GfcD}_{\mathrm{Cter} \beta \mathrm{b}}$, and $\mathrm{Yjb} \mathrm{H}_{\mathrm{Cter} \beta \mathrm{b}}$ sequences as well. In addition, the $\beta$-barrel sequences of $\mathrm{BcsC}\left(\mathrm{BcsC}_{\beta \mathrm{b}}\right.$, from PDB: 6TZK) (Acheson et al., 2019) and AlgE (from PDB: 4AFK) (Tan et al., 2014) were also included, given their porin functions in the synthase-dependent cellulose and alginate production pathways, respectively (Whitney \& Howell, 2013). Finally, we also included the sequence of Wzi (PDB: 2YNK) lacking the plug domain $\left(\mathrm{Wzi}_{\beta \mathrm{b}}\right)$, as this is an 18-stranded $\beta$-barrel known to be linked with polysaccharide biosynthesis clusters (Bushell et al., 2013).

Altogether, this analysis detected $365 \beta$-barrel query homologues encoded near 344 OPX proteins of all three classes (Table 1). Of the 156 matches to the Wzi $\beta$ p query, 128 were of comparable size and conserved alignment to full-length Wzi (including the $\alpha$-helical plug domain), consistent with these hits not being likely porin candidates. However, 28 homologues were a match to only $\mathrm{Wzi}_{\beta \mathrm{b}}$ (i.e. no plug domain), reinforcing their candidacies as trans-OM export $\beta$-barrels;

428 intriguingly, HHpred analysis of these 28 hits also revealed many with strong similarity to DUF6029, 429 ascribing a potential polysaccharide secretion role to this heretofore uncharacterized protein domain.

430 The PgaA $\beta$ b query detected 12 homologues, 2 of which were uniquely-matched to only the $\beta$-barrel 
431 domain, whereas the remaining 10 aligned with full-length PgaA, consistent with these latter hits

432 possessing the numerous N-terminal TPR domains as well as the C-terminal PgaA $\beta b$ porin domain.

433 These results were similar for $\mathrm{BcsC}_{\beta \mathrm{b}}$, i.e. that of the 5 homologues detected near OPX proteins, each

434 was a match to full-length $\mathrm{BcsC}$ indicating a conservation of $\mathrm{N}$-terminal TPR and $\mathrm{C}$-terminal porin

435 domains (with no matches confined to $\mathrm{BcsC}_{\beta b}$ detected). Fifteen homologues to synthase-dependent

436 pathway AlgE were also detected. Profile matches to $\mathrm{GfcD}_{\mathrm{Cter} \beta \mathrm{b}}$ and $\mathrm{YjbH}_{\mathrm{Cter} \beta \mathrm{b}}$ queries (68 and 84,

437 respectively) were largely matched via length and conserved alignment to full-length GfcD and

$438 \mathrm{YjbH}$, suggesting that these homologues contain the N-terminal FapF-like $\beta$-barrel domain as well as

439 the C-terminal PgaA $\beta b$-like polymer-secretion domains; only two $\mathrm{GfcD}_{\mathrm{Cter} \beta \mathrm{b}}$ and three $\mathrm{YjbH}_{\mathrm{Cter} \beta \mathrm{b}}$ hits

440 were identified with homology to only the C-terminal barrels of each protein. However, the

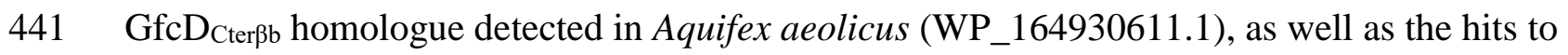

$442 \mathrm{YjbH}_{\mathrm{Cter \beta b}}$ detected in A. aeolicus (WP_010880290.1) and Sulfitobacter pseudonitzschiae

443 (WP_174861591.1), were only matched to the respective polysaccharide-secretion modules,

444 indicating the potential for stand-alone export of sugar chains in these systems. Finally, homologues

445 to MXAN_7418, MXAN_3226, and MXAN_1916 were only found to be encoded in myxobacterial

446 genomes. Importantly, the presence of these extended $\operatorname{PgaA}_{\beta b}$-like 18-stranded $\beta$-barrels in

447 myxobacteria was linked to nearby Class 3 OPX proteins. However, unlike OPX hits from the

448 MYXO database, only 77/2017 Class 3 OPX proteins from the REP dataset were identified to be

449 encoded near MXAN_7418/3226/1916/ $\mathrm{PgaA}_{\beta \mathrm{b}} / \mathrm{GfcD}_{\mathrm{Cter} \beta \mathrm{b}} / \mathrm{YjbH}_{\mathrm{Cter} \beta \mathrm{b}} / \mathrm{BcsC}_{\beta \mathrm{b}} / \mathrm{AlgE} / \mathrm{Wzi} \beta \mathrm{b}$ stand-alone

450 porin homologues.

Together, these data reveal intriguing architectural similarities between $\beta$-barrel porin

452 modules from synthase-dependent polymer export pathways and those implicated in myxobacterial

$453 \mathrm{Wzx} / \mathrm{Wzy}$-dependent secretion, as well as analogous or ABC transporter-dependent pathways in

454 diverse bacteria, all previously unreported associations. 
455 Figure 5. OPX-companion $\boldsymbol{\beta}$-barrel structures. A) Tertiary structure models (top and front views) 456 for MXAN_7418, MXAN_3226, and MXAN_1916, as generated using deep learning via AlphaFold2, 457 as well as the PgaA C-terminal domain (aa 513-807) X-ray crystal structure (PDB: 4Y25) (Wang et 458 al., 2016). Structures are coloured with a spectrum, from the $\mathrm{N}$-terminus (blue) to the C-terminus 459 (red), and depicted with smooth loops. B) Front and back views of the interior spaces of the $\beta$ 460 barrels depicted in Panel A overlaid with the electrostatic character of the residues contacting the 461 lumenal volume, as generated via HOLLOW (Ho \& Gruswitz, 2008). Surfaces have been colored 462 according to charge, from blue (positive, $+5 \mathrm{kT} / \mathrm{e}$ ) to white (uncharged/hydrophobic), to red 463 (negative, $-5 \mathrm{kT} / \mathrm{e})$. C) Trypan Blue dye-binding for M. xanthus DZ2 WT $(\mathrm{n}=6), \Delta$ pilA $(\mathrm{n}=4)$, $464 \Delta w z a X(n=3)$, and $\Delta m x a n \_7418$ (i.e. $\Delta w z p X, \mathrm{n}=4$ ) to probe cell-surface EPS levels. Mean values 465 are indicated (+/- SEM), with each biological replicate data point indicated. Means of all mutants 466 were significantly lower than WT, while that of $\Delta m x a n \_7418$ was significantly higher than either $467 \Delta$ pilA or $\Delta w z a X$, as calculated via Student's T-test $(p<0.05)$. D) T4P-dependent swarm expansion 468 of strains tested in Panel C. Scale bar: $4 \mathrm{~mm}$. E) Auto-aggregation profiles of strains tested in Panel $469 \mathrm{C}$ for cells resuspended in CYE rich medium at an initial $\mathrm{OD}_{600}$ of 1.0. Mean values $(\mathrm{n}=3)$ are 470 indicated +/- SEM. Open plot points: no statistically significant difference in mean relative to $\Delta w z a X$ 471 at a given time point. Closed plot points: statistically significant difference of means relative to $472 \Delta w z a X$ at a given time point. Significance was evaluated via Student's T-test $(p \leq 0.05)$. 
bioRxiv preprint doi: https://doi.org/10.1101/2022.02.11.480155; this version posted February 12, 2022. The copyright holder for this preprint (which was not certified by peer review) is the author/funder, who has granted bioRxiv a license to display the preprint in perpetuity. It is made available under aCC-BY-NC 4.0 International license.

\section{FIGURE 5}

A)

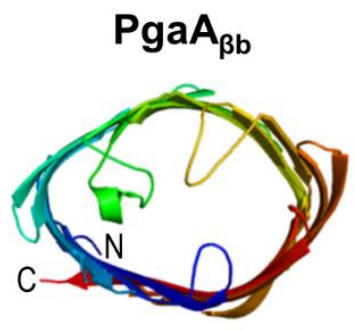

$90^{\circ}$

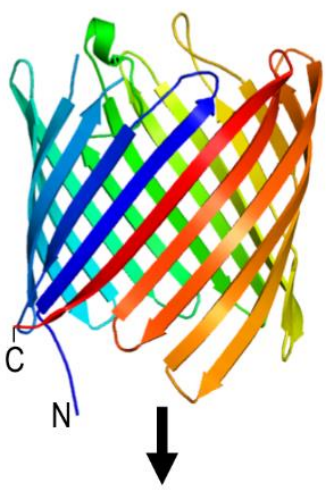

B)
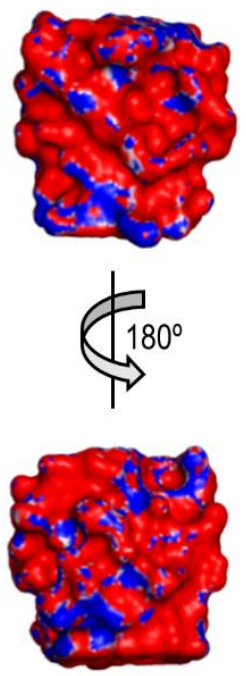
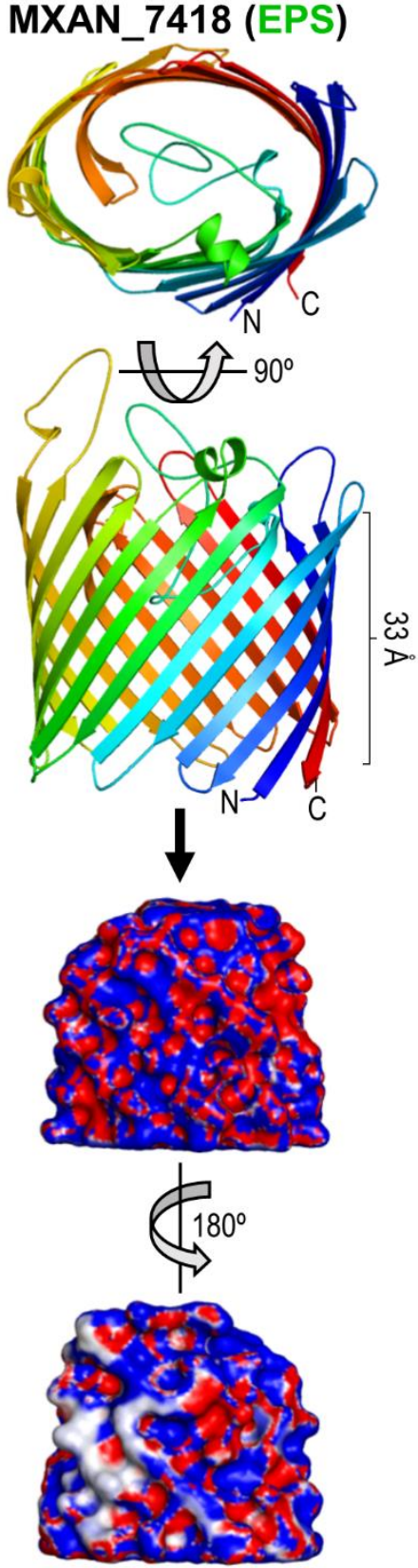

D)

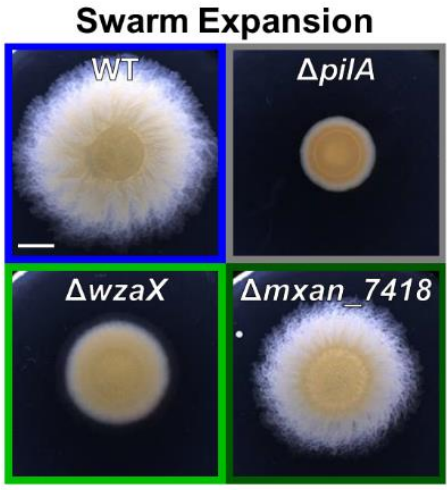

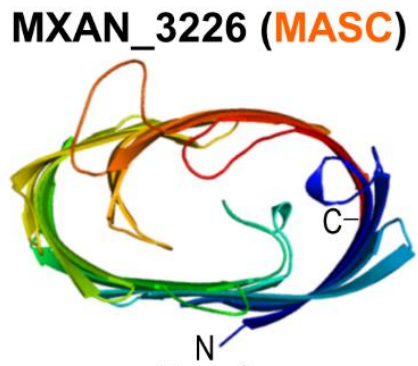

MXAN_1916 (BPS)
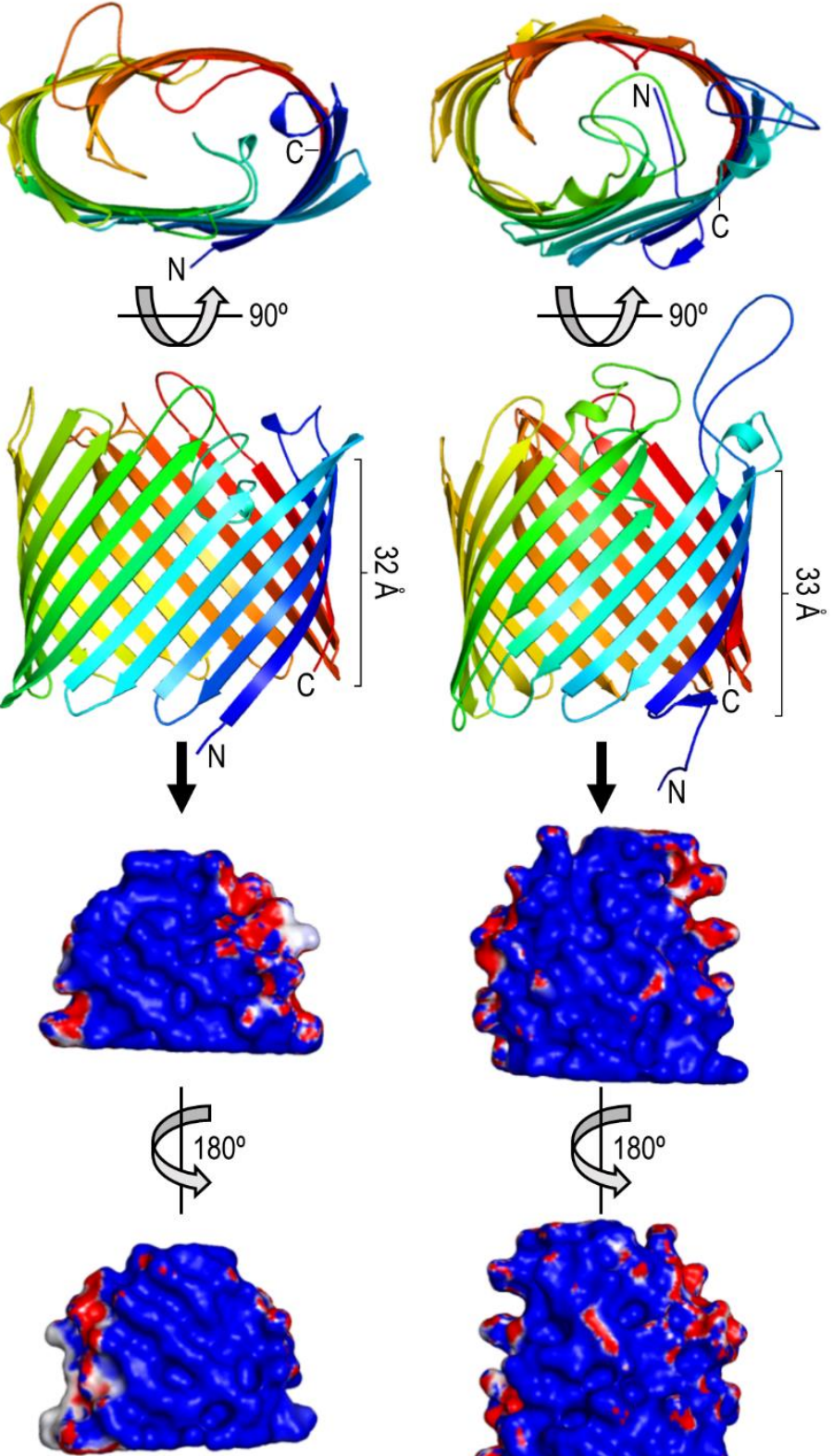

E)

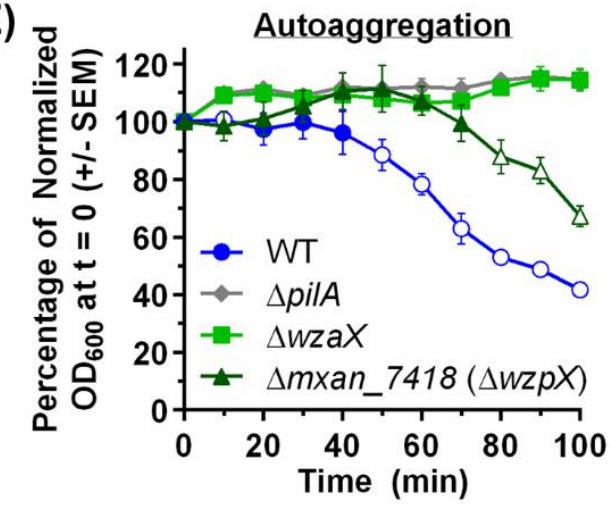

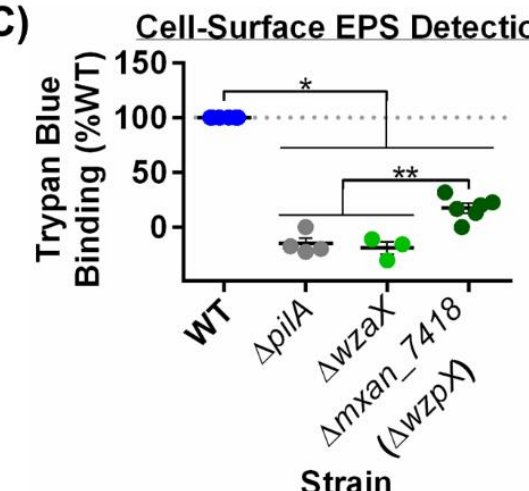

Strain 


\section{porins}

476

To examine the structural suitability of the $\mathrm{WzaX} / \mathrm{S} / \mathrm{B}$ co-occurring $\beta$-barrels for the respective translocation of EPS/MASC/BPS, and since no full-length template structure could be identified, we employed the deep-learning approach provided by AlphaFold 2 to generate a tertiary structure model. AlphaFold2 employs information from evolutionarily-coupled amino acids as well as templates with structural homology to fold a polypeptide sequence using an iterative process (Jumper et al., 2021). Consistent with the above-described data (Supplementary Figs. 2,3,4), MXAN_7418, 3226, and 1916 were all predicted to form 18-stranded $\beta$-barrels with sizeable central cavities, with respective barrel heights of 33, 32, and $33 \AA$ (Fig. 5A). As molecular dynamics simulations typically calculate the hydrophobic thickness of asymmetric OM bilayers to be $\sim 40 \%$ of their total solvated thickness (Pavlova et al., 2016), based on our measured M. xanthus OM thickness of $69.8 \pm 1.8 \AA$ (Fig. 4A), an approximated hydrophobic thickness of $\sim 28 \AA$ would indeed by traversable by the proposed MXAN_7418, MXAN_3226, and MXAN_1916 tertiary structures.

We subsequently used HOLLOW to probe the lumenal volume of the EPS/MASC/BPScluster $\beta$-barrels via filling of the internal space with dummy atoms to generate a cast of the void space, after which the electrostatic potential of the contacting $\beta$-barrel surface was overlaid. To validate this approach, we first probed the internal electrostatics of the $\mathrm{PgaA}_{\beta \mathrm{b}}$ template structure, revealing a highly anionic interior (Fig. 5B), consistent with passage of the cationic PNAG polymer through the lumen of the barrel. BPS was previously discovered to be a randomly-acetylated anionic repeating tetrasaccharide, with the distal three sugars of each repeat constituted by mannosaminuronic acid (ManNAcA) units (Islam et al., 2020). Therefore, the cationic charge character of the MXAN_1916 lumen (Fig. 5B) is indeed suitable for passage of its associated HMW BPS polymer. While the chemical structures or exact compositions of MASC or EPS are not known, isolated spore coat material was found to contain GalNAc chains with potential glucose (Glc) and glycine decorations (Holkenbrink et al., 2014). As the interior of the MXAN_3226 $\beta$-barrel is cationic (Fig. 5B), this suggests that MASC may have a net-anionic charge character, as contributed via as-yet-unidentified sugars and/or chemical modifications. EPS composition has been probed across four investigations (Islam et al., 2020, Behmlander \& Dworkin, 1994, Gibiansky et al., 2013, Sutherland \& Thomson, 1975), with Ara, Gal, GalNAc, Glc, GlcN, GlcNAc, Man, ManNAc, Rha, and Xyl having been identified (depending on the publication); however, none of these sugars are 
highly charged, which is consistent with the more neutral character of the MXAN_7418 interior (compared to that of either MXAN_1916 or MXAN_3226) (Fig.5B).

To probe the implication of Wzx/Wzy-dependent pathway-associated $\beta$-barrels in polymer secretion, we next set out to better understand their physiological contexts. RNAseq analysis previously detected the transcripts encoding MXAN_7418 and MXAN_1916 in vegetative cells, as well as MXAN_3226 in developmental cells, indicating that all three $\beta$-barrels are indeed expressed over the course of the M. xanthus lifecycle (Muñoz-Dorado et al., 2019, Sharma et al., 2021).

512 Furthermore, MXAN_1916 was detected in proteomic screens of biotinylated surface-exposed

513 proteins, and MXAN_1916 and MXAN_3226 were both detected in OMV samples from vegetative cells (Kahnt et al., 2010). Importantly, the MXAN_3226 $\beta$-barrel was already shown to be an essential part of the MASC pathway as its respective $M$. xanthus deletion-mutant strain was found to be deficient in sporulation and MASC production (Holkenbrink et al., 2014). To examine effects of $\beta$-barrel deletion on EPS levels in vegetative cells, we first generated a $\Delta$ mxan_7418 chromosomal deletion mutant strain. Since retention of Trypan Blue has become a well-established indicator for the presence of EPS on the surface of $M$. xanthus cells, we next compared the dye-binding capacity of $\Delta$ mxan_7418 cells versus EPS-pathway $\mathrm{OPX}^{-}(\Delta w z a X)$ and $\mathrm{T}^{-} \mathrm{P}^{-}(\Delta p i l A)$ cells, both known to be defective in EPS production. Relative to WT cells, absence of the EPS-pathway $\beta$-barrel resulted in an $83 \%$ loss of Trypan Blue retention by $\Delta m x a n \_7418$ cells (Fig. 5C), indicating a severe reduction in the amount of cell-surface EPS in the $\beta$-barrel mutant, consistent with cell-surface EPS deficiencies previously probed in $\Delta w z x X, \Delta w z y X, \Delta w z c X, \Delta w z e X$, and $\Delta w z a X$ EPS-pathway mutants (Islam et al., 2020).

Compared to the baseline readings in the $\Delta w z a X$ EPS-pathway $\mathrm{OPX}^{-}$mutant strain, $\Delta m x a n \_7418$ cells displayed marginally higher levels of Trypan Blue binding (Fig. 5C). These results are consistent with EPS-pathway $\beta$-barrel deficiency principally impacting polymer export to the cell surface, as opposed to both polymer assembly and export being compromised in the absence of EPS-pathway OPX proteins. To probe whether residual quantities of EPS were indeed present on

531 the surface of $\Delta m x a n \_7418$ cells, we compared swarm expansion on solid medium as well as auto-

532 aggregation in liquid medium; though both phenotypes are multifactorial, each requires T4P

533 engagement with cell-surface EPS. Relative to WT, $\Delta$ mxan_7418 swarm expansion was reduced,

534 with this phenotype even more pronounced in $\Delta w z a X$ swarms (Fig. 5D). Similarly for auto-

535 aggregation testing in rich medium, consistent with previous findings, WT cells steadily clumped 
536 together and sedimented in the cuvette, whereas both $\Delta p i l A$ and $\Delta w z a X$ cells did not (Fig. 5E). Cells

537 of the $\Delta m x a n \_7418$ mutant remained in suspension analogous to $\Delta w z a X$ cells for $\sim 75 \%$ of the assay,

538 after which they began to slowly sediment (Fig. 5E), suggesting that cell-surface EPS had eventually

539 accumulated to a sufficient threshold to support T4P-mediated clumping in liquid. Taken together,

540 these data indicate that while minimal amounts of EPS can reach the cell surface through as-yet-

541 undetermined means (see Discussion for further comment), MXAN_7418 serves as the principal

542 trans-OM conduit for EPS export in M. xanthus.

543 Ultimately, the findings detailed in this investigation support a model for polysaccharide

544 export in Wzx/Wzy-dependent pathways lacking an integral OM OPX protein — as represented by

545 the independent EPS, BPS and MASC pathways in M. xanthus - in which the final polymer must

546 pass through an integral OM $\beta$-barrel porin for efficient secretion to the cell exterior. For these

547 reasons, as well as the long-established naming convention for Wzx/Wzy-dependent pathways in

548 bacteria (Reeves et al., 1996), we propose the designation Wzp (i.e. Wz porin) for the newly-

549 identified component of these secretion systems (Fig. 6). 
550 Figure 6. Wzx/Wzy-dependent polysaccharide assembly-and-secretion pathways in $M$.

551 xanthus. In these schematics, the WzaX/S/B proteins have been depicted in a linking capacity

552 between the apex of the WzcX/S/B PCP periplasmic domains and the periplasmic opening of the

553 integral OM WzpX/S/B $\beta$-barrel porins identified herein. However, (i) the exposure of the

554 EPS/MASC/BPS polymers to the periplasmic space as each transits between the IM and OM

555 components of each system, and (ii) the exact role(s) of the WzaX/S/B proteins in M. xanthus

556 polymer translocation (Supplementary Fig. S6), remain open questions for each pathway. To

557 denote these uncertainties, this stage of the transport cycle has been marked with an asterisk $\left({ }^{*}\right)$. 
bioRxiv preprint doi: https://doi.org/10.1101/2022.02 11.480155; this version posted February 12, 2022. The copyright holder for this preprint (which was not certified by peer review) is the author/funder, who has granted bioRxiv a license to display the preprint in perpetuity. It is made available under aCC-BY-NC 4.0 International license.

\section{FIGURE 6}

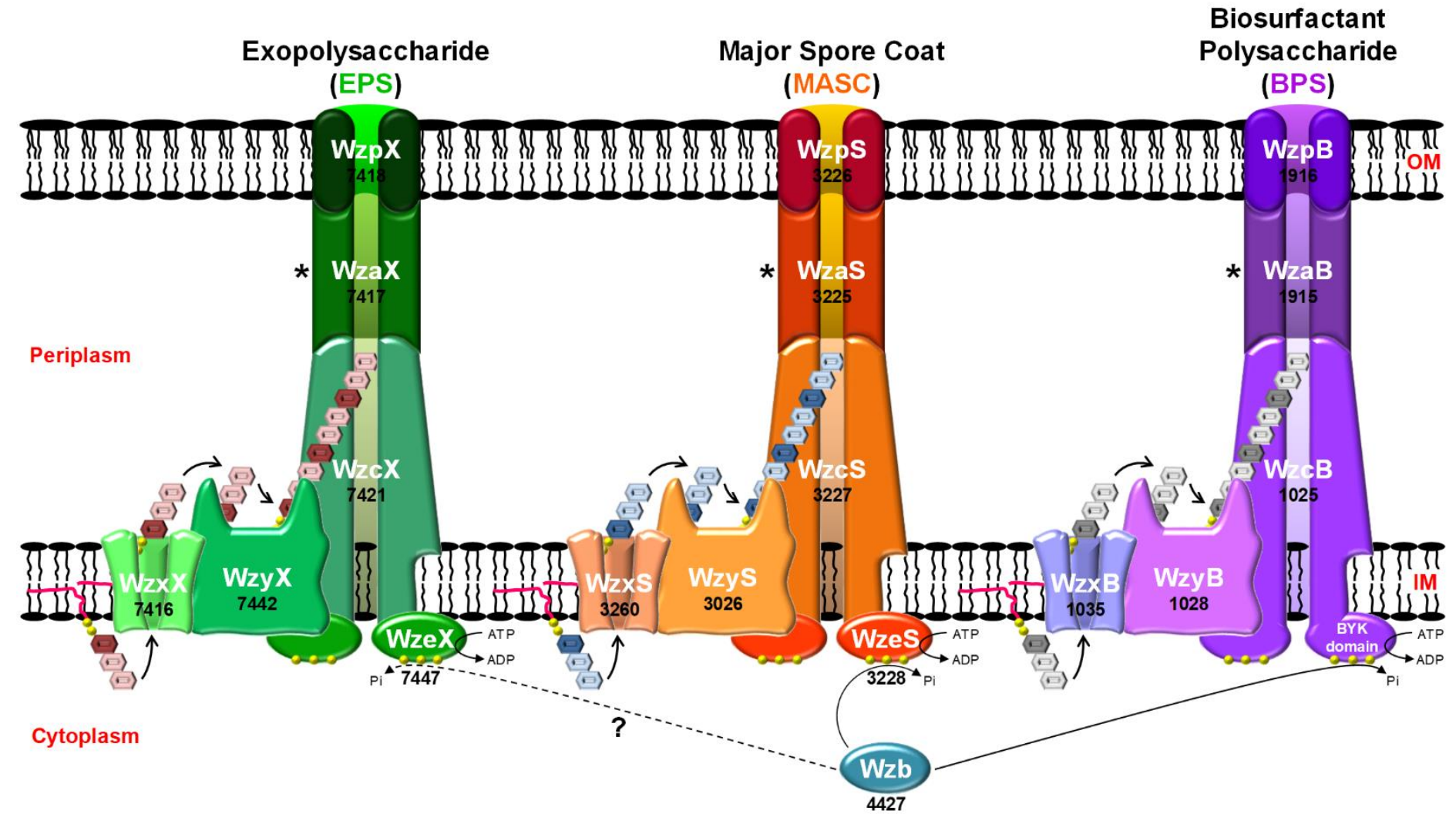




\section{DISCUSSION}

Knowledge of the terminal component through which secreted polysaccharides exit a bacterial cell is crucial for the development of targeted antimicrobial agents that could be used to inhibit this process (Kong et al., 2013). From the data presented herein, we have provided evidence that bacterial OPX proteins fall into one of three distinct structural classes, the first two of which have either the demonstrated (Class 1) or predicted (Class 2) capacity to span the OM, whereas the third (Class 3) is missing any such domains. Instead, as demonstrated by the Class 3 OPX WzaX/S/B proteins from $M$. xanthus, these Wzx/Wzy-dependent pathway proteins are genomically and functionally paired with a complementary integral OM-spanning $\beta$-barrel porin similar to that required for PNAG export in synthase-dependent pathways.

The Class 1 OPX protein WzaEc is the most extensively-characterized OPX protein with respect to structure-function relationships. The orientation of $\mathrm{Wza}_{E c}$ in the $\mathrm{OM}$ was established through introduction of a FLAG tag on the $\mathrm{Wza}_{E c}$ C-terminus, allowing for a FLAG epitope to be detected on the cell surface with $\alpha$-FLAG antibodies (Dong et al., 2006). Similar introduction of a Cterminal His6 epitope tag resulted in a partially functional $\mathrm{Wza}_{E c}-\mathrm{His}_{6}$ construct that was able to restore K30 Group 1 CPS biosynthesis to $\sim 20 \%$ of the level restored by an untagged WzaEc construct following expression in trans (Nesper et al., 2003). Various C-terminal $\alpha$-helix truncations also abolished $\mathrm{Wza}_{E c}$ function (Ford et al., 2009). This indicates that the OM-spanning domain of Wza $\mathrm{Ec}_{c}$ can be functionally-sensitive to structural perturbation. In lipid bilayers, purified $\mathrm{Wza}_{E c}-\mathrm{His}_{6}$ was able to form 2D octameric ring-like crystal arrays (Beis et al., 2004), suggestive of channel formation, with this arrangement confirmed by the 3D X-ray crystal structure (Dong et al., 2006). Through introduction of the photo-crosslinkable synthetic amino acid $p$-benzoyl-L-phenylalanine ( $p$ Bpa) at various sites in $\mathrm{Wza}_{E c}$, Nickerson and colleagues elegantly demonstrated that K30 CPS polymers could be trapped in the lumen of the translocon (Nickerson et al., 2014), confirming that sites within periplasmic D2 (Fig. 1A) were able to maintain translocon functionality as well as form crosslinks with polymers. Site-specific $p$ Bpa substitutions within periplasmic D1 rendered Wza $\mathrm{E}_{E}$ non-functional. Conversely, $p \mathrm{Bpa}$-substituted positions in periplasmic D3, and more importantly at the kink in the OM-traversing $\alpha$-helical D4, maintained Wza $E c$ functionality, but were unable to form detectable intermolecular crosslinks upon UV exposure (Nickerson et al., 2014). As such, the transit 
technique. However, purified $\mathrm{Wza}_{E c}$ was shown to stably insert into planar lipid bilayers and form electro-conductive channels, with site-specific amino acids substitutions confirming that ion flow does indeed proceed via the D4 pore formed by the OM-spanning $\alpha$-helix (Kong et al., 2013). Synthetic peptides corresponding to the native $\mathrm{Wza}_{E c}$ D4 $\alpha$-helix sequence were also able to

594 spontaneously insert into such bilayers, but formed unstable pores; however, modification of the native D4 sequence through consensus generation (based on 94 closely-related sequences) yielded an optimized peptide (Fig. 2B) that could spontaneously insert into bilayers and form stable pores (Mahendran et al., 2017). Given the primary structure diversity amongst OM-spanning $\alpha$-helices uncovered herein for both Class 1 and Class 2B OPX proteins (Fig. 2B,C), additional optimization of synthetic peptide sequences should be possible to further improve spontaneous membrane insertion, self-assembly, and $\alpha$-barrel pore stability. export. When expressed in isolation, $\mathrm{KpsD}_{E c}$ was shown to reside in the periplasm (Silver et al., 1987). However, upon expression of $\mathrm{KpsD}_{E c}$ along with its cognate IM-localized PCP KpsE (which extends into the periplasm), $\mathrm{KpsD}_{E c}$ was also detected in IM and OM fractions of lysed cells (Arrecubieta et al., 2001). Intriguingly, OM-localized $\mathrm{Kps}_{E c}$ is detected as a multimer, whereas the minimally-detected IM-localized $\mathrm{KpsD}_{E c}$ is present as a monomer, consistent with the adoption of quaternary structure by $\mathrm{KpsD}_{E c}$ at the site of polysaccharide egress from the cell (Sande et al., 2019). Furthermore, immunolabelling of intact $E$. coli cells using $\alpha-\mathrm{KpsD}_{E c}$ antiserum resulted in the detection of $\mathrm{KpsD}_{E c}$ epitopes at the cell surface (McNulty et al., 2006), suggesting that a portion of $\mathrm{KpsD}_{E c}$ was indeed surface-accessible. The detection herein of structural homology of the extreme $\mathrm{KpsD}_{E c} \mathrm{C}$-terminus to the OM-spanning domain of $\mathrm{Wza}_{E c}$ further supports the contention that a part of $\mathrm{KpsD}_{E c}$ is able to interact with, and span, the OM bilayer, albeit in a conditional manner. The 24residue length of the $\mathrm{KpsD}_{E c} \mathrm{C}$-terminal $\alpha$-helix is well within the threshold of 20 amino acids required to span the hydrophobic core of a membrane bilayer for $\alpha$-helical integral membrane domains (Baeza-Delgado et al., 2013). Analogous to $\mathrm{Wza}_{E c}$, truncation of the $\mathrm{KpsD}_{E c} \mathrm{C}$-terminus by

61611 amino acids abrogated protein function (Wunder et al., 1994). A potential OM-spanning $\alpha$-helix

617 is indeed a conserved property of the Class 2B OPX proteins identified in this study. Despite the 618 detectability of $\mathrm{KpsD}_{E c}$ at the cell surface with $\alpha-\mathrm{KpsD}_{E c}$ antibodies, $\alpha$-His-tag antibodies were 619 unable to label the surface of cells expressing a $\mathrm{KpsD}_{E c}$ variant encoding a C-terminal His6 affinity 620 tag (McNulty et al., 2006); in this instance, the highly-cationic nature of the affinity tag may have 621 impeded its translocation across the hydrophobic OM bilayer, thus inhibiting immunodetection. 
622 Given that $\mathrm{KpsD}_{E c}$ by itself does not intrinsically associate with the OM (Silver et al., 1987), this

623 may suggest that the protein can become directly inserted into the OM (as opposed to requiring OM

624 insertion via the Bam/Tam or Lol machinery). In this manner, $\mathrm{Kps}_{E c}$ could indeed function as the

625 terminal piece of the Group 2 capsule secretion machinery.

Historically, Group 2 CPS secretion across the OM had been suggested to implicate integral OM $\beta$-barrel porins (Whitfield \& Valvano, 1993, Bliss \& Silver, 1996), however such a model has fallen out of favour given that no such $\beta$-barrels have ever been detected in or near related Kps synthesis clusters. This would be consistent with an ability of $\mathrm{KpsD}_{E c}$-like Class $2 \mathrm{~B}$ OPX proteins to traverse the OM, thus not requiring any downstream piece of export machinery in certain organisms. However, this scenario may not be absolute, as numerous instances of $\beta$-barrel proteins encoded near both Class 2A and Class 2B (as well as Class 1 and Class 3) OPX genes were uncovered herein,

633 suggesting that integral OM porins may play an important role in non-synthase-dependent secretion in diverse organisms. Though not all Class 2 OPX proteins identified in our investigation were matched with a nearby $\beta$-barrel, our synteny analysis window was limited to $+/-10$ genes from each

636 OPX gene and would thus not have captured candidate porins elsewhere in the genome. As a case-

637 in-point, the $M$. xanthus EPS, MASC, and BPS clusters contain respective insertions of $>18 \mathrm{kbp}$,

$638>223 \mathrm{kbp}$, and > $1 \mathrm{Mbp}$ that separate constituent members of the same cluster, which in the latter

639 results in extraordinary genomic distance between $w z a B$-wzpB and the remainder of the BPS

640 assembly genes (Islam et al., 2020). Moreover, as our synteny analyses were limited to 9 query 641 sequences ( 8 with similarity to $\mathrm{PgaA}_{\beta b}$ ), this does not preclude the presence of other/more distantly642 related $\beta$-barrels near "unmatched" OPX proteins. However, in the absence of specific templates 643 with which to search, such an analysis was beyond the scope of the current investigation.

The identification of "OPX" proteins (an obvious misnomer) in Gram-positive bacteria, but

645 specifically those of Class 3 architecture, point to a broadly-conserved periplasmic function for these 646 proteins, likely through interfacing with the periplasmic domains of PCP proteins in most organisms. 647 However, as dedicated peptidoglycan-spanning polysaccharide export channels have yet to be 648 identified in Gram-positive bacteria, any role for Class 3 OPX proteins in these systems with regards 649 to interactions with a secretion pore of some sort would be unfounded speculation. In M. xanthus 650 cells, WzaX/S/B Class 3 OPX protein deficiency does not lead to visible accumulations of polymeric 651 material in the periplasm (Saïdi et al., 2021) suggesting that EPS/MASC/BPS polymer assembly via 652 Wzx/Wzy-dependent pathways does not indiscriminately continue in these mutant backgrounds; this 
653 is a similar observation to that for $\mathrm{Wza}_{E c}$ Class 1 OPX deficiency in E. coli cells (Nesper et al.,

654 2003). Such material from ABC transporter-dependent synthesis does however accumulate in the

655 periplasm of $\mathrm{KpsD}_{E c}$-deficient Class 2B OPX-mutant cells (Wunder et al., 1994, Bliss \& Silver, 656 1996).

For myxobacterial Class 3 OPX proteins, a clear partnership has now been demonstrated between these secretion-pathway components and integral OM $\beta$-barrel porins illustrating the requirement of the latter for HMW polysaccharide export across the OM. The WzpS (MXAN_3226) $\beta$-barrel was already shown to be essential for MASC secretion, but its function in the MASC transport cycle was not known at the time (Holkenbrink et al., 2014). In the current investigation, we have shown that the properties of WzpB (MXAN_1916) make it suitable for BPS translocation across the OM. Furthermore, we have herein demonstrated that WzpX (MXAN_7418) functions as the principal export conduit for EPS across the OM to the cell surface. Intriguingly, EPS still appears to be assembled to a certain degree in mutant cells lacking WzpX (given the residual amount detected on the cell surface), as opposed to cells lacking WzaX which manifest an even more robust EPS ${ }^{-}$ phenotype. This may indicate that while lack of the OPX component in the EPS pathway results in a severe reduction (or shutdown) of EPS production, in cells lacking WzpX, other $\beta$-barrel porins (e.g. WzpS and/or WzpB) may be able to inefficiently cross-complement the deficiency in the EPSpathway machinery, resulting in residual EPS localization to the cell surface. Part of this inefficiency could arise from the cationic natures of the $\mathrm{WzpS}$ and $\mathrm{WzpB}$ barrel interiors not serving as suitable conduits for a more neutral EPS polymer.

The presence of a Wza_C domain in a Class 1 or 2B OPX protein is not mutually exclusive to the presence of an integral OM $\beta$-barrel protein encoded nearby, considering that such barrels were found to be encoded near genes representing all three OPX protein classes across a range of bacterial genomes. The GfcD protein is particularly intriguing given the GfcE protein also encoded by the 677 Group 4 CPS export locus (Peleg et al., 2005). While GfcD contains a PgaA $\beta$ b-like polysaccharide 678 secretion component with an attached SLBB-like domain (as part of the GfcD C-terminal module) 679 (Supplementary Fig. 5B), GfcE is a functional Class 1 OPX paralogue of Wza ${ }_{E c}$; this was 680 evidenced by the ability of GfcE (formerly YccZ/Wza22min) expressed in trans to partially restore $E$. 681 coli K30 CPS production in a mutant lacking WzaEc (Drummelsmith \& Whitfield, 2000). GfcE 682 possesses a complete Wza_C domain, and as such would be expected to span the OM in a WzaEc-like 683 manner. One possibility could be that the Wza_C domain of the GfcE OPX protein may be required 
684

685

686

687

688

689

690

691

692

693

694

695

696

697

698

699

700

701

702

703

704

705

706

707

708

709

710

711

712

713

to properly interact/organize around the $\mathrm{GfcD}_{\mathrm{Cter} \beta \mathrm{b}}$ polysaccharide secretion module. Furthermore, the presence of a putative FapF amyloid secretion $\beta$-barrel fused to the same polypeptide as that of a PgaA $_{\beta b}$-like module typically associated with polysaccharide secretion raises an interesting possibility. Amyloid proteins are frequently secreted by bacteria in order to stabilize biofilm matrices composed largely of secreted polysaccharides (Erskine et al., 2018). Thus, in Group 4 capsules, secretion of amyloidogenic polypeptides (via the GfcD FapF-like N-terminal module) could help to stabilize the polysaccharide component of the capsule structure and/or anchor the CPS to the cell surface.

\section{Ideas and Speculation}

For Class 3 OPX proteins, the lack of OM-spanning domains and the (relatively) small size of these proteins (compared to other OPX classes), present a dilemma regarding the mechanism of transit across the periplasm for polymers produced by these systems (Supplementary Fig. 6). As a case-in-point, the thickness of the M. xanthus periplasm was measured to be $327 \AA$ (Fig. 4A,B), while the periplasmic domain of the BPS-pathway WzcB PCP-2B protein was estimated to extend up to $\sim 165 \AA$ into the periplasmic space. Coupled with the maximum possible height of $\sim 62 \AA$ for one unit of OPX protein WzaB, together this only accounts for $\sim 227 \AA$ of periplasmic thickness, leaving $\sim 100 \AA$ of periplasmic height unaccounted for (Supplementary Fig. 6), compared to standard models of polysaccharide secretion (Fig. 1A). Furthermore, high-confidence co-evolving amino acids between WzcB and WzaB localize to the apex of the PCP and the base of the Poly_export domain of the Class 3 OPX protein (respectively) (Supplementary Fig. 6, Supplementary Table S5), heavily implying the presence of a conserved interaction interface between the two proteins. With the assumption of pathway specificity for each M. xanthus Class 3 OPX protein - as evidenced by lack of cross-complementation in single-OPX-knockout strains (Islam et al., 2020) and using components of the BPS pathway as examples (Fig. 6), several potential models for transenvelope transit can thus be proposed:

(i) Model 1: As the polymer exits the WzcB cavity in the periplasm (following WzyBmediated polymerization), it passes through a periplasmic WzcB-associated single-layer WzaB oligomer. Once past this point, the polymer would have to independently locate its cognate integral $\mathrm{OM} W z p B \beta$-barrel porin in order to reach the outside of the cell. This presumes the polymer is 
714

715

716

717

718

719

720

721

722

723

724

725

726

727

728

729

730

731

732

733

734

735

736

737

738

739

740

741

742

743

exposed to the periplasm for a substantial portion of its trip between the IM and OM. In such a model, polymer export might still be possible in the absence of the cognate OPX (as long as this absence does not impact polymer assembly). However, since this is not the case in M. xanthus, it would argue against this model.

(ii) Model 2: This is a variation of Model 1 in which single-layer periplasmic oligomers of $\mathrm{WzaB}$ are located both on the apical point of the PCP octamer as well as the proximal face of the integral OM WzpB $\beta$-barrel porin. In this manner, $M$. xanthus OPX-mediated substrate specificity would exist at both ends of the transport process, but again the polymer could be exposed to the periplasm during stages of the transport cycle bridging the OPX proteins. Nonetheless, this model provides a solution to the question of "targeting" of the nascent polymer to the proper OM-spanning apparatus. However, this model also presumes a constant presence of Class 3 OPX proteins associated with the OM, as well as specific interactions between the periplasmic OPX WzaB and the integral OM porin $\mathrm{WzpB}$. At the moment, this is not bolstered by high-confidence evolutionary couplings data between the two proteins (Supplementary Table S5), but this may be partially due to an insufficient number of barrel homologues with which to fully probe coevolution. However, as OPX proteins are not detected in surface-biotinylated or OMV samples from M. xanthus, supporting evidence for this concept is lacking.

(iii) Model 3: The periplasmic distance of $327 \AA$ could be approximately accounted for by $\sim 165 \AA$ of WzcB PCP-2B periplasmic domain height, followed by OPX oligomers of WzaB stacked in duplicate $(\sim 62 \AA \times 2=\sim 124 \AA)$ or triplicate $(\sim 62 \AA \times 3=\sim 186 \AA)$, depending on the packing arrangement of the oligomers. Along with the PCP channel, such architecture could be envisaged to form a protected channel lumen spanning from the IM to the OM, precluding exposure of the polymer to the periplasm. This would also abrogate any "targeting" issues of the polymer to the WzpB $\beta$-barrel secretin. In this case, HMW oligomers of $M$. xanthus OPX proteins would be expected in the periplasm, which could possibly co-precipitate with IM and/or OM fractions. Once again, data to support this contention awaits further experimentation.

(iv) Model 4: As the nascent polymer emerges from the PCP-2B opening, the polymer interacts with copies of $\mathrm{WzaB}$ at the apex of the PCP-2B periplasmic domain, allowing WzaB to bind the polymer and detach from the PCP. As additional polymer elongation occurs, more units of WzaB are able to bind further down the polymer. In this manner, WzaB bound to the polymer would serve 
744 as a type of targeting chaperone which preferentially directs the periplasmic polymer to its cognate

745 WzpB $\beta$-barrel porin in the OM. Once a given WzaB has reached the porin, it would disengage from

746 the polymer and be able to undergo subsequent rounds of binding in the periplasm to the nascent

747 polymer. Such a mechanism would afford a certain degree of protection to the translocating polymer

748 against the periplasmic environment, as well as provide a mechanism for targeting of the polymer to

749 the specific $\beta$-barrel machinery needed for transport across the OM. This would also explain why the

750 Class 3 OPX proteins WzaX, WzaS, and WzaB were not detected in screens of surface-biotinylated

751 proteins or those identified in OMV fractions (from vegetative and developmental cells), i.e. that OM

752 association of $\mathrm{WzaX} / \mathrm{S} / \mathrm{B}$ (via interaction with $\mathrm{WzpX} / \mathrm{WzpS} / \mathrm{WzpB}$ ) is of a more transient nature.

Exposure of a sugar polymer to the periplasm as it transits between the IM and OM is a

common occurrence in synthase-dependent systems such as those involved in alginate, cellulose, and

PNAG assembly-and-export (Whitney \& Howell, 2013). Recently, Group 2 CPS was also suggested

to be exposed to the periplasm at some point during its secretion across the cell envelope (Liston et

$a l ., 2018)$. In these systems, periplasmic enzymes are able to access the transiting polymer and introduce various modifications including sugar epimerization and/or (de)acetylation. Such a mechanism may be in place for the $M$. xanthus BPS polymer, for which the secreted form displays random acetylation (Islam et al., 2020). In synthase-dependent pathways, TPR domains (either standalone or attached) extend into the periplasm from the $\beta$-barrel porin and are proposed to interact with these chain-modifying enzymes (Whitney \& Howell, 2013). Of note, numerous OPX proteins were found to be encoded near $\beta$-barrel genes for full-length PgaA and $\mathrm{BcsC}$ homologues complete with the respective TPR architectures (Table 1). In these systems, questions arise as to the functional relationships between periplasmic OPX proteins and integral OM $\beta$-barrel porins with TPR domains potentially occluding access of the OPX protein to the periplasmic face of the porin. the well-studied WzaEc protein, which will further our understanding of the mechanism of sugar polymer export in bacterial cells. Moreover, updated genomic, structural, and functional knowledge of the terminal step in the polysaccharide secretion pathway will enable researchers to selectively develop novel antimicrobial compounds targeted to blocking bacterial polymer secretion from the

772 outside, thus bypassing any requirements for access to the cell interior to compromise the viability of 773 a bacterial cell. 


\section{MATERIALS AND METHODS}

775

776

777

778

779

780

781

782

783

784

785

786

787

788

789

790

791

792

793

794

795

796

797

798

799

800

801

802

803

804

805

\section{Protein structure analysis \& modelling}

Given the high fold-recognition equivalence between WzaX/S/B and Wza $\mathrm{Wc}_{c}$, the tertiary structure of each $M$. xanthus OPX protein was modelled against the Wza $E c$ template (PDB: 2J58) using MODELLER. For $\beta$-barrel proteins MXAN_7418/3226/1918 that lacked a suitable full-length structural template, protein structure models were computed using deep learning and artificial intelligence via AlphaFold2 (Jumper et al., 2021). Multiple sequence alignment entries were generated using 606, 251 and 101 unique sequences, respectively for MXAN_1916, MXAN_3226 and MXAN_7418, with the program run for 5 independent prediction models, leading to convergence after 3 recycling iterations. For proteins $\mathrm{GfcD}$ and $\mathrm{YjbH}$, deposited AlphaFold2-generated structures were mined from the UniProt entries for P75882 and P32689, respectively. HOLLOW (Ho \& Gruswitz, 2008) was used to generate internal volume casts of the MXAN_7418/3226/1918 $\beta$ barrels, followed by overlaying of the solvent-accessible electrostatic potential contributed by amino acids in contact with the internal volume, as calculated using PDB2PQR and APBS (Propka pH 7.0, Swanson force field, $\pm 5 \mathrm{kT} / \mathrm{e})$. All protein structures were visualized and rendered in PyMol. Evolutionarily-coupled amino acids within the same protein were analyzed using RaptorX-Contact (Wang et al., 2017), while evolutionarily-coupled residues between two proteins were determined using RaptorX-ComplexContact (Zeng et al., 2018) (http://raptorx.uchicago.edu/). Protein contact maps were displayed in GraphPad.

\section{Identification of OPX proteins}

Three types of datasets i.e., 61 order Myxococcales genomes (MYXO), 3662 reference and representative bacterial genomes (REP; downloaded on Dec 7, 2021), and non-redundant NCBI database (NR) (371 327556 proteins at 100\% identify as of June 10, 2021) were downloaded from NCBI. Pfam domains attributed to PF02563 [Poly_export], PF10531 [SLBB], PF18412 [Wza_C], and PF06251 [Caps_synth_GfcC; used here as GfcC] were extracted from the Pfam-A v34.0 database (Mistry et al., 2021) (downloaded: March 24, 2021) and a reduced combined profile database was created. These functional domains were identified by scanning all three types of datasets (MYXO, REP, and NR) using offline hmmscan (Potter et al., 2018) against the created database with an E-value cutoff of $1 \times 10^{-5}$. The resultant files were parsed using hmmscan-parser.sh, sorted and arranged in the form of protein architecture using in-house scripts. Based on the identified domains per protein per dataset, three primary clusters were curated. All identified proteins within 
these primary clusters were subjected to fold-recognition analysis using HHpred (Söding et al., 2005) against the database of two proteins (PDB: $2 J 58$ [i.e. Wza ${ }_{E c}$ ] and PDB: 3 P42 [i.e. GfcC]; extracted from PDBmmCIF70 downloaded on Nov 19, 2021) using “-p 5 -Z 500 -loc -z 1 -b 1 -B 500 -all -id 35 -ssm 2 -sc 1 -seq 1 -dbstrlen 10000 -norealign -maxres 32000” parameters. HHpred raw data was parsed using in-house scripts to generate the architecture of each protein in terms of non-overlapping

811 homologous regions to $2 \mathrm{~J} 58$ and 3P42. To identify the type of signal peptide and the cleavage site

812 location, each OPX protein was subject to SignalP 6.0 analysis (Teufel et al., 2022) and to predict the 813 membrane topology of the proteins, TMHMM (Server v. 2.0) (Krogh et al., 2001) was used.

814 Based on HHpred analysis, we also investigated the secondary structure-based homology of 815 primary cluster proteins with a Wza_C segment (aa 326 - 359; 34 amino acid length) in PDB 2J58. If

816 a protein was showing secondary structural homology with at least 10/34 amino acids of the Wza_C

817 segment (aa 326 - 359) in 2J58, we considered it as a true Wza_C segment in the respective protein.

818 Proteins with both 2J58- and 3P42-homologous non-overlapping regions were classified as Class 2.

819 Proteins having only 2J58-homologous regions along with a Wza_C segment were classified as Class

820 1. Other proteins with only 2J58-homologous regions and no Wza_C segment were classified as

821 Class 3. We also generated sequence logos using WebLogo (Crooks et al., 2004) (v.2.8) for $2^{\circ}$

822 structure-based homologues of Wza_C segments as identified in Class 1 and Class 2B OPX proteins.

\section{Synteny analysis of $\beta$-barrel query proteins with identified OPX proteins}

Along with the identification of the above-mentioned domains and classification of all OPX

826 proteins into three classes, we identified the $\beta$-barrel homologues encoded in the vicinity ( \pm 10 genes)

827 of our OPX genes in genomes from both the MYXO and REP databases. We analyzed the various

828 predicted proteomes of both datasets with BLASTp and hmmscan using protein sequences from $M$.

829 xanthus DZ2 (MXAN_7418 [aa 24 - 415], MXAN_3226 [aa 23 - 381], and MXAN_1916 [aa 26 -

830 421]), E. coli K12 (PgaA [aa 511 - 807], GfcD [aa 425 - 698], YjbH [aa 423 - 698], BcsC [aa 785 -

831 1157], and Wzi [aa 92 - 479], as well as P. aeruginosa PAO1 AlgE [aa 33 - 490]. Detected

832 homologues for each query profile were aligned against the truncated and full-length sequences for

833 each query protein using Clustal Omega to probe for the lone presence of a putative $\beta$-barrel

834 polysaccharide secretion porin domain versus its presence as part of a multi-domain polypeptide

835 comparable to the native sequence. Hits resembling truncated versions of various $\beta$-barrel queries

836 were individually profiled via fold-recognition using the online HHpred bioinformatics toolkit

837 (Zimmermann et al., 2018) (https://toolkit.tuebingen.mpg.de/tools/hhpred). Depicted sequence 
838 alignments were displayed in GeneDoc with residues colored according to conservation score (out of

839 10) as indicated in JalView (Waterhouse et al., 2009).

Phylogenetic analysis of $\mathrm{OPX}$ proteins

842 The PF02563 [Poly_export] domain of OPX proteins was used as a phylogenetic marker. The

843 locations of all identified 'Poly_export' domains were first extracted, after which extracted sequences

844 were aligned using MUSCLE (with 10 iterations). The resultant alignment was analyzed via

845 FastTree 2.1.10 to generate a maximum likelihood tree of OPX proteins. Tree visualization as well as

846 mapping of the OPX protein classification and taxonomy of each branch were performed via the

847 iTOL web server Version 6.4.3 (Letunic \& Bork, 2021).

848

\section{Bacterial membrane modeling and intermembrane distance measurements}

Desired prokaryotic tomograms were downloaded from the Caltech Electron Tomography

851 Database (https://etdb.caltech.edu/). Forty species were analyzed, each via three separate tomograms.

852 Tomogram inspection and modeling were performed using the IMOD software package (Kremer et

853 al., 1996). Tomograms were first oriented in 3D using the IMOD "Slicer" window to identify the

854 central slice through each bacterium. To enhance contrast, 5 layers of voxels were averaged around

855 the section of interest. Model points were then placed along corresponding regions of the OM and IM

856 for a total distance of $\sim 100 \mathrm{~nm}$. A custom Python script was subsequently used to calculate the

857 intermembrane distance every $0.1 \mathrm{~nm}$ along the modeled stretch of membranes. GraphPad was used

858 to prepare plots and carry out correlation analyses.

Bacterial cell culture

861 Information on wild-type M. xanthus DZ2 (Campos \& Zusman, 1975) and isogenic mutant

862 strains analyzed herein can be found in Table 2. Strains were grown and maintained at $32{ }^{\circ} \mathrm{C}$ on

863 Casitone-yeast extract (CYE) (1\% casitone, $0.5 \%$ yeast extract, $10 \mathrm{mM}$ MOPS [pH 7.5], $4 \mathrm{mM}$

$\left.864 \mathrm{MgSO}_{4}\right) 1.5 \%$ agar (BD Difco) plates or in CYE liquid medium at $32{ }^{\circ} \mathrm{C}$ on a rotary shaker at 220

$865 \mathrm{rpm}$.

\section{Mutant construction}

868 As previously described (Islam et al., 2020), to generate a M. xanthus deletion-mutant strain, 869500 bp upstream and 500 bp downstream of the target gene were amplified and fused via PCR, 
subjected to double digestion with restriction enzymes, then ligated into the pBJ114 plasmid.

871 Products were used to transform chemically-competent E. coli DH10B via heatshock, after which

872 cells were plated on LB agar supplemented with kanamycin $(50 \mu \mathrm{g} / \mathrm{mL})$ to select for drug-resistant

873 colonies. Successful clones were verified via sequencing. Resultant plasmids were then introduced

874 into M. xanthus DZ2 via electroporation. Mutants resulting from homologous recombination of

875 deletion alleles were obtained by selection on CYE agar plates containing kanamycin $(100 \mu \mathrm{g} / \mathrm{mL})$.

876 A second selection was then made on CYE agar plates containing galactose (2.5\%) to obtain the final

877 deletion strain, with mutants verified via PCR amplification using flanking primers.

\section{Trypan blue dye retention}

Retention of the dye Trypan Blue was carried out as previously described (Islam et al., 2020).

881 In brief, cells from overnight CYE cultures were first resuspended to OD 6001.0 in TPM buffer.

882 Resuspended cells (or a cell-free blank) $(900 \mu \mathrm{L})$ were then mixed with Trypan Blue solution (100

$883 \mu \mathrm{L}, 100 \mu \mathrm{g} / \mathrm{mL}$ stock concentration) in a microfuge tube and briefly pulsed (1 s) via vortex mixer.

884 Samples were incubated at room temperature, in a tube rack covered with aluminum foil, atop a

885 rocker platform $(1 \mathrm{~h})$ to facilitate dye binding by the cells. Samples were subsequently sedimented

886 (16 $000 \times g, 5 \mathrm{~min})$, after which the top $900 \mu \mathrm{L}$ of blank or clarified supernatant was transferred to a

887 disposable spectrophotometer cuvette. The cell-free "TPM + Trypan Blue" sample was used to blank

888 the spectrophotometer at $585 \mathrm{~nm}$. The absorbance at $585 \mathrm{~nm}\left(\mathrm{~A}_{585}\right)$ was then determined for each

889 clarified supernatant. Finally, absorbance values were normalized to the respective A585 value for the

890 WT of each biological replicate. Sub-zero final values are due to trace amounts of cell debris

891 detected at $585 \mathrm{~nm}$ in individual samples in which absolutely no binding of Trypan Blue occurred.

\section{Phenotypic analyses}

Cells from exponentially-growing cultures were harvested and resuspended in TPM buffer (10 $\mathrm{mM}$ Tris- $\mathrm{HCl}, \mathrm{pH} 7.6,8 \mathrm{mM} \mathrm{MgSO}_{4}$ and $\left.1 \mathrm{mM} \mathrm{KH}_{2} \mathrm{PO}_{4}\right)$ at a final concentration of $\mathrm{OD}_{600}$ 5.0. To study T4P-dependent swarm expansion, this cell suspension $(5 \mu \mathrm{L})$ was spotted onto CYE $0.5 \%$ agar.

897 Plates were incubated at $32{ }^{\circ} \mathrm{C}(72 \mathrm{~h})$, then imaged with an Olympus SZX16 stereoscope with UC90 


\section{Auto-aggregation testing}

903 The protocol followed has been previously detailed (Saïdi et al., 2021). In brief, the turbidity

904 (OD 600$)$ of $M$. xanthus CYE cultures (12.5 mL) grown overnight was determined via

905 spectrophotometer. Specific culture volumes were aspirated, then sedimented via microfuge $(4000 \times$

$906 g, 5 \mathrm{~min}$ ) so pellet resuspension in $1 \mathrm{~mL} \mathrm{CYE}$ broth would yield a final OD 600 of either 1.0. Broth-

907 resuspended cells were then transferred to a polystyrene spectrophotometer cuvette. Resuspensions

908 were strongly aspirated and ejected in the cuvette (10 s) via p200 micropipette, then immediate read

909 for $\mathrm{OD}_{600}(t=0)$ in a spectrophotometer. Time-course readings of $\mathrm{OD}_{600}$ were taken every $10 \mathrm{~min}$ up

910 to $100 \mathrm{~min}$ of monitoring. In between readings, cuvettes were left covered and undisturbed on the

911 benchtop in a cuvette box. All OD 600 readings were normalized to the $\mathrm{OD}_{600}$ determined at $t=0$ for

912 each sample. 


\section{ACKNOWLEDGEMENTS}

914 The authors would like to thank Yossef Lopez de Los Santos for protein modelling feedback,

915 Omaima Rebay for cloning assistance, and Joseph Lam for critical reading of the manuscript. A

916 Discovery operating grant (RGPIN-2016-06637) from the Natural Sciences and Engineering

917 Research Council of Canada (NSERC) supported this work in the lab of S.T.I. as well as studentships

918 for F.S. and N.Y.J. F.S., N.Y.J., and R.B. are recipients of graduate studentships from the PROTEO

919 research network. This work was also supported by (i) a DST-INSPIRE Faculty award to G.S. from

920 the Department of Science and Technology (DST), India, a (ii) DST-INSPIRE Fellowship to U.M.

921 from the DST, India, (iii) partial support from the Department of Electronics, IT, BT, and S\&T of the

922 Government of Karnataka, India to U.M., A.P., and G.S., and (iv) a David and Lucile Packard

923 Fellowship for Science and Engineering (2019-69645) to Y.-W.C. The funders had no role in study

924 design, data collection and interpretation, or the decision to submit the work for publication. The

925 authors declare that the research was conducted in the absence of any commercial or financial

926 relationships that could be construed as a potential conflict of interest. 
bioRxiv preprint doi: https://doi.org/10.1101/2022.02.11.480155; this version posted February 12, 2022. The copyright holder for this preprint

(which was not certified by peer review) is the author/funder, who has granted bioRxiv a license to display the preprint in perpetuity. It is made available under aCC-BY-NC 4.0 International license.

\section{COMPETING INTERESTS}

928 The authors declare no financial or non-financial competing interests. 


\section{AUTHOR CONTRIBUTIONS}

930 STI and GS conceived of and planned the study.

931 UM, AP, and GS performed comparative genomics studies.

932 FS and RB generated mutant strains.

933 FS performed phenotypic, dye-binding, and auto-aggregation analyses.

934 FS and NYJ performed HOLLOW and electrostatics analyses.

935 STI and AM carried out protein modelling.

$936 \mathrm{MM}$ and GJ designed the periplasmic analysis workflow, with analysis by FS.

937 STI, GS, and FS wrote the manuscript.

938 STI and GS generated figures.

939 STI, GS, CC, and YWC contributed personnel and funding support. 


\section{REFERENCES}

941

942

Acheson, J.F., Derewenda, Z.S., and Zimmer, J. (2019) Architecture of the cellulose synthase outer membrane channel and its association with the periplasmic TPR domain. Structure 27: 18551861.e1853.

Arrecubieta, C., Hammarton, T.C., Barrett, B., Chareonsudjai, S., Hodson, N., Rainey, D., and Roberts, I.S. (2001) The transport of Group 2 capsular polysaccharides across the periplasmic space in Escherichia coli: roles for the KpsE and KpsD proteins*. J. Biol. Chem. 276: 42454250 .

Baeza-Delgado, C., Marti-Renom, M.A., and Mingarro, I. (2013) Structure-based statistical analysis of transmembrane helices. Eur. Biophys. J. 42: 199-207.

Becker, A. (2015) Challenges and perspectives in combinatorial assembly of novel exopolysaccharide biosynthesis pathways. Front. Microbiol. 6.

Behmlander, R.M., and Dworkin, M. (1994) Biochemical and structural analyses of the extracellular matrix fibrils of Myxococcus xanthus. J. Bacteriol. 176: 6295-6303.

Beis, K., Collins, R.F., Ford, R.C., Kamis, A.B., Whitfield, C., and Naismith, J.H. (2004) Threedimensional structure of Wza, the protein required for translocation of Group 1 capsular polysaccharide across the outer membrane of Escherichia coli*. J. Biol. Chem. 279: 2822728232.

Bliss, J.M., and Silver, R.P. (1996) Coating the surface: a model for expression of capsular polysialic acid in Escherichia coli K1. Mol. Microbiol. 21: 221-231.

Burroughs, A.M., Balaji, S., Iyer, L.M., and Aravind, L. (2007) A novel superfamily containing the $\beta$-grasp fold involved in binding diverse soluble ligands. Biol. Direct 2: 4.

Bushell, Simon R., Mainprize, Iain L., Wear, Martin A., Lou, H., Whitfield, C., and Naismith, James H. (2013) Wzi Is an outer membrane lectin that underpins group 1 capsule assembly in Escherichia coli. Structure 21: 844-853.

Campos, J.M., and Zusman, D.R. (1975) Regulation of development in Myxococcus xanthus: effect of 3':5'-cyclic AMP, ADP, and nutrition. Proc. Natl. Acad. Sci. U. S. A. 72: 518-522.

Collins, R.F., Beis, K., Dong, C., Botting, C.H., McDonnell, C., Ford, R.C., Clarke, B.R., Whitfield, C., and Naismith, J.H. (2007) The 3D structure of a periplasm-spanning platform required for assembly of group 1 capsular polysaccharides in Escherichia coli. Proc. Natl. Acad. Sci. U. S. A. 104: 2390-2395.

Crooks, G.E., Hon, G., Chandonia, J.-M., and Brenner, S.E. (2004) WebLogo: a sequence logo generator. Genome Res. 14: 1188-1190.

Cuthbertson, L., Mainprize, I.L., Naismith, J.H., and Whitfield, C. (2009) Pivotal roles of the outer membrane polysaccharide export and polysaccharide copolymerase protein families in export of extracellular polysaccharides in Gram-negative bacteria. Microbiol. Mol. Biol. Rev. 73: 155-177.

Dong, C., Beis, K., Nesper, J., Brunkan-LaMontagne, A.L., Clarke, B.R., Whitfield, C., and Naismith, J.H. (2006) Wza the translocon for E. coli capsular polysaccharides defines a new class of membrane protein. Nature 444: 226. 
980

981

982

983

984

985

986

987

988

989

990

991

992

993

994

995

996

997

998

999

1000

1001

1002

1003

1004

1005

1006

1007

1008

1009

1010

1011

1012

1013

1014

1015

1016

1017

1018

1019

Drummelsmith, J., and Whitfield, C. (2000) Translocation of group 1 capsular polysaccharide to the surface of Escherichia coli requires a multimeric complex in the outer membrane. EMBO J. 19: 57-66.

Ducret, A., Valignat, M.-P., Mouhamar, F., Mignot, T., and Theodoly, O. (2012) Wet-surfaceenhanced ellipsometric contrast microscopy identifies slime as a major adhesion factor during bacterial surface motility. Proc. Natl. Acad. Sci. USA 109: 10036-10041.

Erskine, E., MacPhee, C.E., and Stanley-Wall, N.R. (2018) Functional amyloid and other protein fibers in the biofilm matrix. J. Mol. Biol. 430: 3642-3656.

Faure, L.M., Fiche, J.-B., Espinosa, L., Ducret, A., Anantharaman, V., Luciano, J., Lhospice, S., Islam, S.T., Tréguier, J., Sotes, M., Kuru, E., Van Nieuwenhze, M.S., Brun, Y., Théodoly, O., L, A., Nollmann, M., and Mignot, T. (2016) The mechanism of force transmission at bacterial focal adhesion complexes. Nature 539: 530-535.

Ferrières, L., Aslam, S.N., Cooper, R.M., and Clarke, D.J. (2007) The yjbEFGH locus in Escherichia coli $\mathrm{K}-12$ is an operon encoding proteins involved in exopolysaccharide production.

Microbiology 153: 1070-1080.

Ford, R.C., Brunkan-LaMontagne, A.L., Collins, R.F., Clarke, B.R., Harris, R., Naismith, J.H., and Whitfield, C. (2009) Structure-function relationships of the outer membrane translocon Wza investigated by cryo-electron microscopy and mutagenesis. J. Struct. Biol. 166: 172-182.

Franklin, M.J., Nivens, D.E., Weadge, J.T., and Howell, P.L. (2011) Biosynthesis of the Pseudomonas aeruginosa extracellular polysaccharides, alginate, Pel, and Psl. Front. Microbiol. 2: 167.

Gibiansky, M.L., Hu, W., Dahmen, K.A., Shi, W., and Wong, G.C.L. (2013) Earthquake-like dynamics in Myxococcus xanthus social motility. Proc. Natl. Acad. Sci. USA 110: 2330-2335.

Ho, B.K., and Gruswitz, F. (2008) HOLLOW: generating accurate representations of channel and interior surfaces in molecular structures. BMC Struct. Biol. 8: 49.

Holkenbrink, C., Hoiczyk, E., Kahnt, J., and Higgs, P.I. (2014) Synthesis and assembly of a novel glycan layer in Myxococcus xanthus spores. J. Biol. Chem. 289: 32364-32378.

Hu, W., Lux, R., and Shi, W., (2013) Analysis of exopolysaccharides in Myxococcus xanthus using confocal laser scanning microscopy. In: Bacterial Cell Surfaces: Methods and Protocols. A.H. Delcour (ed). Totowa, NJ: Humana Press, pp. 121-131.

Islam, S.T., Eckford, P.D.W., Jones, M.L., Nugent, T., Bear, C.E., Vogel, C., and Lam, J.S. (2013a) Proton-dependent gating and proton uptake by Wzx support O-antigen-subunit antiport across the bacterial inner membrane. mBio 4: e00678-00613.

Islam, S.T., Fieldhouse, R.J., Anderson, E.M., Taylor, V.L., Keates, R.A.B., Ford, R.C., and Lam, J.S. (2012) A cationic lumen in the Wzx flippase mediates anionic O-antigen subunit translocation in Pseudomonas aeruginosa PAO1. Mol. Microbiol. 84: 1165-1176.

Islam, S.T., Gold, A.C., Taylor, V.L., Anderson, E.M., Ford, R.C., and Lam, J.S. (2011) Dual conserved periplasmic loops possess essential charge characteristics that support a catch-andrelease mechanism of O-antigen polymerization by Wzy in Pseudomonas aeruginosa PAO1. J. Biol. Chem. 286: 20600-20605. 
1020

1021

1022

1023

1024

1025

1026

1027

1028

1029

1030

1031

1032

1033

1034

1035

1036

1037

1038

1039

1040

1041

1042

1043

1044

1045

1046

1047

1048

1049

1050

1051

1052

1053

1054

1055

1056

1057

1058

1059

1060

1061

Islam, S.T., Huszczynski, S.M., Nugent, T., Gold, A.C., and Lam, J.S. (2013b) Conserved-residue mutations in Wzy affect O-antigen polymerization and Wzz-mediated chain-length regulation in Pseudomonas aeruginosa PAO1. Sci. Rep. 3: 3441.

Islam, S.T., and Lam, J.S. (2014) Synthesis of bacterial polysaccharides via the Wzx/Wzy-dependent pathway. Can. J. Microbiol. 60: 697-716.

Islam, S.T., and Mignot, T. (2015) The mysterious nature of bacterial surface (gliding) motility: a focal adhesion-based mechanism in Myxococcus xanthus. Semin. Cell Dev. Biol. 46: 143-154.

Islam, S.T., Taylor, V.L., Qi, M., and Lam, J.S. (2010) Membrane topology mapping of the Oantigen flippase (Wzx), polymerase (Wzy), and ligase (WaaL) from Pseudomonas aeruginosa PAO1 reveals novel domain architectures. mBio 1: e00189-00110.

Islam, S.T., Vergara Alvarez, I., Saïdi, F., Guiseppi, A., Vinogradov, E., Sharma, G., Espinosa, L., Morrone, C., Brasseur, G., Guillemot, J.-F., Benarouche, A., Bridot, J.-L., Ravicoularamin, G., Cagna, A., Gauthier, C., Singer, M., Fierobe, H.-P., Mignot, T., and Mauriello, E.M.F. (2020) Modulation of bacterial multicellularity via spatio-specific polysaccharide secretion. PLOS Biol. 18: e3000728.

Jumper, J., Evans, R., Pritzel, A., Green, T., Figurnov, M., Ronneberger, O., Tunyasuvunakool, K., Bates, R., Žídek, A., Potapenko, A., Bridgland, A., Meyer, C., Kohl, S.A.A., Ballard, A.J., Cowie, A., Romera-Paredes, B., Nikolov, S., Jain, R., Adler, J., Back, T., Petersen, S., Reiman, D., Clancy, E., Zielinski, M., Steinegger, M., Pacholska, M., Berghammer, T., Bodenstein, S., Silver, D., Vinyals, O., Senior, A.W., Kavukcuoglu, K., Kohli, P., and Hassabis, D. (2021) Highly accurate protein structure prediction with AlphaFold. Nature 596: 583-589.

Kahnt, J.r., Aguiluz, K., Koch, J.r., Treuner-Lange, A., Konovalova, A., Huntley, S., Hoppert, M., Søgaard-Andersen, L., and Hedderich, R. (2010) Profiling the outer membrane proteome during growth and development of the social bacterium Myxococcus xanthus by selective biotinylation and analyses of outer membrane vesicles. J. Proteome Res. 9: 5197-5208.

Kong, L., Harrington, L., Li, Q., Cheley, S., Davis, B.G., and Bayley, H. (2013) Single-molecule interrogation of a bacterial sugar transporter allows the discovery of an extracellular inhibitor. Nat. Chem. 5: 651-659.

Kremer, J.R., Mastronarde, D.N., and McIntosh, J.R. (1996) Computer visualization of threedimensional image data using IMOD. J. Struct. Biol. 116: 71-76.

Krogh, A., Larsson, B., von Heijne, G., and Sonnhammer, E.L.L. (2001) Predicting transmembrane protein topology with a hidden markov model: application to complete genomes. J. Mol. Biol. 305: $567-580$.

Lavelle, K., Sinderen, D.v., and Mahony, J. (2021) Cell wall polysaccharides of Gram positive ovococcoid bacteria and their role as bacteriophage receptors. Comput. Struct. Biotechnol. J. 19: 4018-4031.

Letunic, I., and Bork, P. (2021) Interactive Tree Of Life (iTOL) v5: an online tool for phylogenetic tree display and annotation. Nucleic Acids Res. 49: W293-W296.

Liston, S.D., McMahon, S.A., Le Bas, A., Suits, M.D.L., Naismith, J.H., and Whitfield, C. (2018) Periplasmic depolymerase provides insight into ABC transporter-dependent secretion of bacterial capsular polysaccharides. Proc. Natl. Acad. Sci. U. S. A. 115: E4870-E4879. 
1062

1063

1064

1065

1066

1067

1068

1069

1070

1071

1072

1073

1074

1075

1076

1077

1078

1079

1080

1081

1082

1083

1084

1085

1086

1087

1088

1089

1090

1091

1092

1093

1094

1095

1096

1097

1098

1099

1100

1101

1102

1103

Mahendran, K.R., Niitsu, A., Kong, L., Thomson, A.R., Sessions, R.B., Woolfson, D.N., and Bayley, H. (2017) A monodisperse transmembrane $\alpha$-helical peptide barrel. Nat. Chem. 9: 411-419.

Mathavan, I., Zirah, S., Mehmood, S., Choudhury, H.G., Goulard, C., Li, Y., Robinson, C.V., Rebuffat, S., and Beis, K. (2014) Structural basis for hijacking siderophore receptors by antimicrobial lasso peptides. Nat. Chem. Biol. 10: 340-342.

McNulty, C., Thompson, J., Barrett, B., Lord, L., Andersen, C., and Roberts, I.S. (2006) The cell surface expression of group 2 capsular polysaccharides in Escherichia coli: the role of KpsD, RhsA and a multi-protein complex at the pole of the cell. Mol. Microbiol. 59: 907-922.

Mistry, J., Chuguransky, S., Williams, L., Qureshi, M., Salazar, Gustavo A., Sonnhammer, E.L.L., Tosatto, S.C.E., Paladin, L., Raj, S., Richardson, L.J., Finn, R.D., and Bateman, A. (2021) Pfam: the protein families database in 2021. Nucleic Acids Res. 49: D412-D419.

Mori, Y., Maeda, M., Takegawa, K., and Kimura, Y. (2012) PhpA, a tyrosine phosphatase of Myxococcus xanthus, is involved in the production of exopolysaccharide. Microbiology 158: 2546-2555.

Muñoz-Dorado, J., Marcos-Torres, F.J., García-Bravo, E., Moraleda-Muñoz, A., and Pérez, J. (2016) Myxobacteria: moving, killing, feeding, and surviving together. Front. Microbiol. 7.

Muñoz-Dorado, J., Moraleda-Muñoz, A., Marcos-Torres, F.J., Contreras-Moreno, F.J., MartinCuadrado, A.B., Schrader, J.M., Higgs, P.I., and Pérez, J. (2019) Transcriptome dynamics of the Myxococcus xanthus multicellular developmental program. eLife 8: e50374.

Nesper, J., Hill, C.M.D., Paiment, A., Harauz, G., Beis, K., Naismith, J.H., and Whitfield, C. (2003) Translocation of group 1 capsular polysaccharide in Escherichia coli serotype K30: structural and functional analysis of the outer membrane lipoprotein Wza*. J. Biol. Chem. 278: 4976349772.

Nickerson, N.N., Mainprize, I.L., Hampton, L., Jones, M.L., Naismith, J.H., and Whitfield, C. (2014) Trapped translocation intermediates establish the route for export of capsular polysaccharides across Escherichia coli outer membranes. Proc. Natl. Acad. Sci. USA 111: 8203-8208.

Pavlova, A., Hwang, H., Lundquist, K., Balusek, C., and Gumbart, J.C. (2016) Living on the edge: simulations of bacterial outer-membrane proteins. Biochim. Biophys. Acta 1858: 1753-1759.

Peleg, A., Shifrin, Y., Ilan, O., Nadler-Yona, C., Nov, S., Koby, S., Baruch, K., Altuvia, S., ElgrablyWeiss, M., Abe, C.M., Knutton, S., Saper, M.A., and Rosenshine, I. (2005) Identification of an Escherichia coli operon required for formation of the O-antigen capsule. J. Bacteriol. 187: 5259-5266.

Pérez-Burgos, M., García-Romero, I., Jung, J., Schander, E., Valvano, M.A., and Søgaard-Andersen, L. (2020) Characterization of the exopolysaccharide biosynthesis pathway in Myxococcus xanthus. J. Bacteriol. 202: e00335-00320.

Pérez-Burgos, M., and Søgaard-Andersen, L. (2020) Biosynthesis and function of cell-surface polysaccharides in the social bacterium Myxococcus xanthus. Biol. Chem. 401: 1375-1387.

Potter, S.C., Luciani, A., Eddy, S.R., Park, Y., Lopez, R., and Finn, R.D. (2018) HMMER web server: 2018 update. Nucl. Acids Res. 46: W200-W204.

Reeves, P.R., Hobbs, M., Valvano, M.A., Skurnik, M., Whitfield, C., Coplin, D., Kido, N., Klena, J., Maskell, D., Raetz, C.R.H., and Rick, P.D. (1996) Bacterial polysaccharide synthesis and gene nomenclature. Trends Microbiol. 4: 495-503.

Page 50 of 68 
1104

1105

1106

1107

1108

1109

1110

1111

1112

1113

1114

1115

1116

1117

1118

1119

1120

1121

1122

1123

1124

1125

1126

1127

1128

1129

1130

1131

1132

1133

1134

1135

1136

1137

1138

1139

1140

1141

1142

1143

1144

Rouse, S.L., Hawthorne, W.J., Berry, J.-L., Chorev, D.S., Ionescu, S.A., Lambert, S., Stylianou, F., Ewert, W., Mackie, U., Morgan, R.M.L., Otzen, D., Herbst, F.-A., Nielsen, P.H., Dueholm, M., Bayley, H., Robinson, C.V., Hare, S., and Matthews, S. (2017) A new class of hybrid secretion system is employed in Pseudomonas amyloid biogenesis. Nat. Commun. 8: 263.

Rutten, L., Geurtsen, J., Lambert, W., Smolenaers, J.J.M., Bonvin, A.M., de Haan, A., van der Ley, P., Egmond, M.R., Gros, P., and Tommassen, J. (2006) Crystal structure and catalytic mechanism of the LPS 3-O-deacylase PagL from Pseudomonas aeruginosa. Proc. Natl. Acad. Sci. U. S. A. 103: 7071-7076.

Saïdi, F., Jolivet, N.Y., Lemon, D.J., Nakamura, A., Belgrave, A.M., Garza, A.G., Veyrier, F.J., and Islam, S.T. (2021) Bacterial glycocalyx integrity drives multicellular swarm biofilm dynamism. Mol. Microbiol. 116: DOI: 10.1111/mmi.14803.

Sande, C., Bouwman, C., Kell, E., Nickerson, N.N., Kapadia, S.B., and Whitfield, C. (2019) Structural and functional variation in outer membrane polysaccharide export (OPX) proteins from the two major capsule assembly pathways present in Escherichia coli. J. Bacteriol. 201: e00213-00219.

Sande, C., and Whitfield, C. (2021) Capsules and extracellular polysaccharides in Escherichia coli and Salmonella. EcoSal Plus 9: eESP-0033-2020.

Sathiyamoorthy, K., Mills, E., Franzmann, T.M., Rosenshine, I., and Saper, M.A. (2011) The crystal structure of Escherichia coli Group 4 capsule protein $\mathrm{GfcC}$ reveals a domain organization resembling that of Wza. Biochemistry 50: 5465-5476.

Seef, S., Herrou, J., de Boissier, P., My, L., Brasseur, G., Robert, D., Jain, R., Mercier, R., Cascales, E., Habermann, B.H., and Mignot, T. (2021) A Tad-like apparatus is required for contactdependent prey killing in predatory social bacteria. eLife 10: e72409.

Sharma, G., Yao, A.I., Smaldone, G.T., Liang, J., Long, M., Facciotti, M.T., and Singer, M. (2021) Global gene expression analysis of the Myxococcus xanthus developmental time course. Genomics 113: 120-134.

Silver, R.P., Aaronson, W., and Vann, W.F. (1987) Translocation of capsular polysaccharides in pathogenic strains of Escherichia coli requires a 60-kilodalton periplasmic protein. $J$. Bacteriol. 169: 5489-5495.

Smaldone, G.T., Jin, Y., Whitfield, D.L., Mu, A.Y., Wong, E.C., Wuertz, S., and Singer, M. (2014) Growth of Myxococcus xanthus in continuous-flow-cell bioreactors as a method for studying development. Appl. Environ. Microbiol. 80: 2461-2467.

Söding, J., Biegert, A., and Lupas, A.N. (2005) The HHpred interactive server for protein homology detection and structure prediction. Nucl. Acids Res. 33: W244-W248.

Solan, R., Pereira, J., Lupas, A.N., Kolodny, R., and Ben-Tal, N. (2021) Gram-negative outermembrane proteins with multiple $\beta$-barrel domains. Proc. Natl. Acad. Sci. U. S. A. 118: e2104059118.

Sutherland, I.W., and Thomson, S. (1975) Comparison of polysaccharides produced by Myxococcus strains. J. Gen. Microbiol. 89: 124-132.

Tan, J., Rouse, S.L., Li, D., Pye, V.E., Vogeley, L., Brinth, A.R., El Arnaout, T., Whitney, J.C., Howell, P.L., Sansom, M.S.P., and Caffrey, M. (2014) A conformational landscape for 
alginate secretion across the outer membrane of Pseudomonas aeruginosa. Acta Crystallogr. D Biol. Crystallogr. 70: 2054-2068.

Teufel, F., Almagro Armenteros, J.J., Johansen, A.R., Gíslason, M.H., Pihl, S.I., Tsirigos, K.D., Winther, O., Brunak, S., von Heijne, G., and Nielsen, H. (2022) SignalP 6.0 predicts all five types of signal peptides using protein language models. Nat. Biotechnol.

Toh, E., Kurtz, H.D., and Brun, Y.V. (2008) Characterization of the Caulobacter crescentus holdfast polysaccharide biosynthesis pathway reveals significant redundancy in the initiating glycosyltransferase and polymerase steps. J. Bacteriol. 190: 7219-7231.

Wang, S., Sun, S., Li, Z., Zhang, R., and Xu, J. (2017) Accurate de novo prediction of protein contact map by ultra-deep learning model. PLOS Comput. Biol. 13: e1005324.

Wang, Y., Andole Pannuri, A., Ni, D., Zhou, H., Cao, X., Lu, X., Romeo, T., and Huang, Y. (2016) Structural basis for translocation of a biofilm-supporting exopolysaccharide across the bacterial outer membrane*. J. Biol. Chem. 291: 10046-10057.

Wartel, M., Ducret, A., Thutupalli, S., Czerwinski, F., Le Gall, A.-V., Mauriello, E.M.F., Bergam, P., Brun, Y.V., Shaevitz, J., and Mignot, T. (2013) A versatile class of cell surface directional motors gives rise to gliding motility and sporulation in Myxococcus xanthus. PLoS Biol. 11: e1001728.

Waterhouse, A.M., Procter, J.B., Martin, D.M.A., Clamp, M., and Barton, G.J. (2009) Jalview Version 2-a multiple sequence alignment editor and analysis workbench. Bioinformatics 25: 1189-1191.

Whitfield, C., and Valvano, M.A., (1993) Biosynthesis and expression of cell-surface polysaccharides in Gram-negative bacteria. In: Advances in Microbial Physiology. A.H. Rose (ed). Academic Press, pp. 135-246.

Whitfield, C., Wear, S.S., and Sande, C. (2020) Assembly of bacterial capsular polysaccharides and exopolysaccharides. Annu. Rev. Microbiol. 74: 521-543.

Whitney, J.C., and Howell, P.L. (2013) Synthase-dependent exopolysaccharide secretion in Gramnegative bacteria. Trends Microbiol. 21: 63-72.

Willis, L.M., and Whitfield, C. (2013) Structure, biosynthesis, and function of bacterial capsular polysaccharides synthesized by $\mathrm{ABC}$ transporter-dependent pathways. Carbohydr. Res. 378: $35-44$.

Wirth, C., Condemine, G., Boiteux, C., Bernèche, S., Schirmer, T., and Peneff, C.M. (2009) NanC crystal structure, a model for outer-membrane channels of the acidic sugar-specific KdgM porin family. J. Mol. Biol. 394: 718-731.

Wunder, D.E., Aaronson, W., Hayes, S.F., Bliss, J.M., and Silver, R.P. (1994) Nucleotide sequence and mutational analysis of the gene encoding KpsD, a periplasmic protein involved in transport of polysialic acid in Escherichia coli K1. J. Bacteriol. 176: 4025-4033.

Yang, Y., Liu, J., Clarke, B.R., Seidel, L., Bolla, J.R., Ward, P.N., Zhang, P., Robinson, C.V., Whitfield, C., and Naismith, J.H. (2021) The molecular basis of regulation of bacterial capsule assembly by Wzc. Nat. Commun. 12: 4349.

Zeng, H., Wang, S., Zhou, T., Zhao, F., Li, X., Wu, Q., and Xu, J. (2018) ComplexContact: a web server for inter-protein contact prediction using deep learning. Nucleic Acids Res. 46: W432W437. 
1187 Zimmermann, L., Stephens, A., Nam, S.-Z., Rau, D., Kübler, J., Lozajic, M., Gabler, F., Söding, J., 1188 Lupas, A.N., and Alva, V. (2018) A completely reimplemented MPI Bioinformatics Toolkit with a new HHpred server at its core. J. Mol. Biol. 430: 2237-2243.

1190

1191 
1192 TABLE 1. $\beta$-barrels identified to be syntenic with OPX genes in the REP dataset.

\begin{tabular}{|c|c|c|c|c|c|}
\hline $\begin{array}{l}\beta \text {-Barrel } \\
\text { Query } \\
\text { Template }\end{array}$ & $\begin{array}{l}\text { Total } \beta \text {-Barrel } \\
\text { Homologues } \\
\text { Detected Near } \\
\text { OPX Genes }\end{array}$ & $\begin{array}{l}\beta \text {-Barrel } \\
\text { Homologues } \\
\text { Detected Near } \\
\text { Class } 1 \text { OPX } \\
\text { Genes }\end{array}$ & $\begin{array}{l}\beta \text {-Barrel } \\
\text { Homologues } \\
\text { Detected Near } \\
\text { Class 2A OPX } \\
\text { Genes }\end{array}$ & $\begin{array}{l}\beta \text {-Barrel } \\
\text { Homologues } \\
\text { Detected Near } \\
\text { Class 2B OPX } \\
\text { Genes }\end{array}$ & $\begin{array}{l}\beta \text {-Barrel } \\
\text { Homologues } \\
\text { Detected Near } \\
\text { Class } 3 \text { OPX } \\
\text { Genes }\end{array}$ \\
\hline MXAN 7418 & MXAN 7418: 6 & - & - & - & 6 \\
\hline MXAN_3226 & MXAN_3226: 9 & - & - & - & 9 \\
\hline MXAN_1916 & MXAN_1916: 12 & - & - & - & 12 \\
\hline \multirow[t]{2}{*}{$\mathrm{PgaA}_{\beta b}$} & PgaA: $\quad 8$ & 3 & - & 1 & 4 \\
\hline & $\mathrm{PgaA}_{\beta \mathrm{b}}:$ & 2 & - & - & - \\
\hline \multirow[t]{2}{*}{ GfcD $_{\text {Cter } \beta b}$} & GfcD: & 44 & 4 & 18 & - \\
\hline & $\mathrm{GfcD}_{\mathrm{Cter \beta b}}:$ & - & 1 & 1 & - \\
\hline \multirow[t]{2}{*}{$\mathrm{YjbH}_{\mathrm{Cter} \beta b}$} & YjbH: & 55 & 5 & 19 & - \\
\hline & $\mathrm{YjbH}_{\mathrm{Cter \beta b}}:$ & 1 & 1 & 1 & - \\
\hline \multirow[t]{2}{*}{$\mathrm{BcsC}_{\beta b}$} & BcsC: & 1 & - & - & 4 \\
\hline & $\mathrm{BcsC}_{\beta b}:$ & - & - & - & - \\
\hline $\mathrm{AlgE}$ & AlgE: & 6 & - & 2 & 6 \\
\hline \multirow[t]{2}{*}{$\overline{W z i_{\beta b}}$} & Wzi: & 44 & 9 & 48 & 32 \\
\hline & Wzi $i_{\beta b}:$ & 5 & 1 & 14 & 8 \\
\hline
\end{tabular}


bioRxiv preprint doi: https://doi.org/10.1101/2022.02.11.480155; this version posted Februarv 12. 2022. The copvriaht holder for this preprint (which was not certified by peer review) is the author/funder, who has granted bioRxiv a license to display the preprint in perpetuity. It is made available under aCC-BY-NC 4.0 International license.

1194 TABLE 2. Myxococcus xanthus strains used in this study.

\begin{tabular}{|c|c|c|}
\hline Strain & Genotype/Description & Source or Reference \\
\hline SI1 & DZ2 (wild type) & (Campos \& Zusman, 1975) \\
\hline TM389 & $\Delta p i l A\left(\Delta m x a n \_5783\right)$ & (Ducret et al., 2012) \\
\hline TM469 & $\Delta$ wzaX (i.e. $\left.\Delta m x a n \_7417 / e p s Y\right)$ & (Ducret et al., 2012) \\
\hline SI93 & $\Delta w z p X$ (i.e. $\left.\Delta m x a n \_7418 / e p s X\right)$ & This study \\
\hline
\end{tabular}


1196 Supplementary Figure S1. Structural homology between Wza $\mathbf{E c}_{c}$ and KpsD $\mathrm{D}_{E c \text {. }}(\mathrm{A})$ Fold-

1197 recognition analysis of $\mathrm{KpsD}_{E c}$ (via HHpred) revealing C-terminal structural homology to GfcC (PDB:

1198 3P42) as well as Wza $E_{E c}$ (PDB: 2J58). (B) Profile-based alignment of Wza $E_{c}$ and KpsD $E_{C}$ C-terminal

1199 sequences from Panel A. Wza ${ }_{E c} \alpha$-helix (dark green cylinders) and $\beta$-strand (dark blue arrows)

1200 structure is depicted as per the 2J58 PDB entry. $\mathrm{KpsD}_{E c}$ predicted a-helix (light green cylinders) and

$1201 \beta$-strand (light blue arrows) secondary structure is indicated as per PSIPRED analysis. Aligned

1202 residues have been coloured according to Jalview conservation score (out of 10). Maroon, 10; red,

1203 9; orange, 8; yellow, 7; pink, 6. Scores of 5 or less have been omitted to improve clarity of the

1204 figure. The end of $\mathrm{KpsD}_{E c}$ structural homology with the stand-alone GfcC protein has been indicated

1205 as per a previous report (Sande et al., 2019). (C) Tertiary structure model of the KpsD $\mathrm{EC}_{C}$ C-terminus

1206 based on structural alignment with $\mathrm{Wza}_{E_{c}}$ as indicated in Panel B. N- and C-termini of the displayed

1207 peptide have been indicated. 
bioRxiv preprint doi: https://doi org/10.1101/2022 02 11.480155 this version posted February 12, 2022. The copyright holder for this preprint (which was not certified by peer review) is the author/funder, who has granted bioRxiv a license to display the preprint in perpetuity. It is made available under aCC-BY-NC 4.0 International license.

\section{SUPPLEMENTARY FIGURE S1}

A)

1

$\mathrm{KpsD}_{E c}$

$\mathrm{Wza}_{E c}$

GfcC

2.J58_c

B)

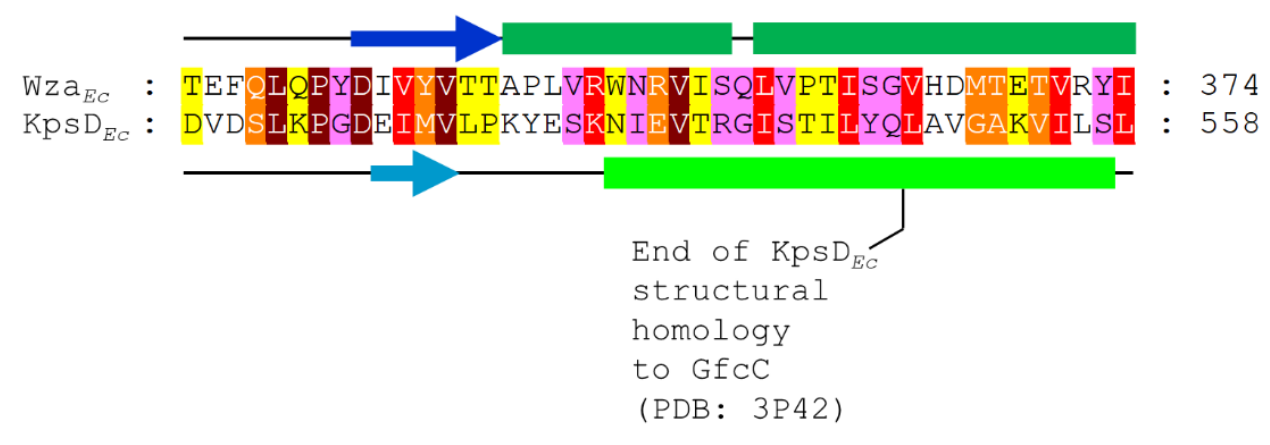

C)

Wza $_{E c}$

$\mathrm{KpsD}_{E c}$
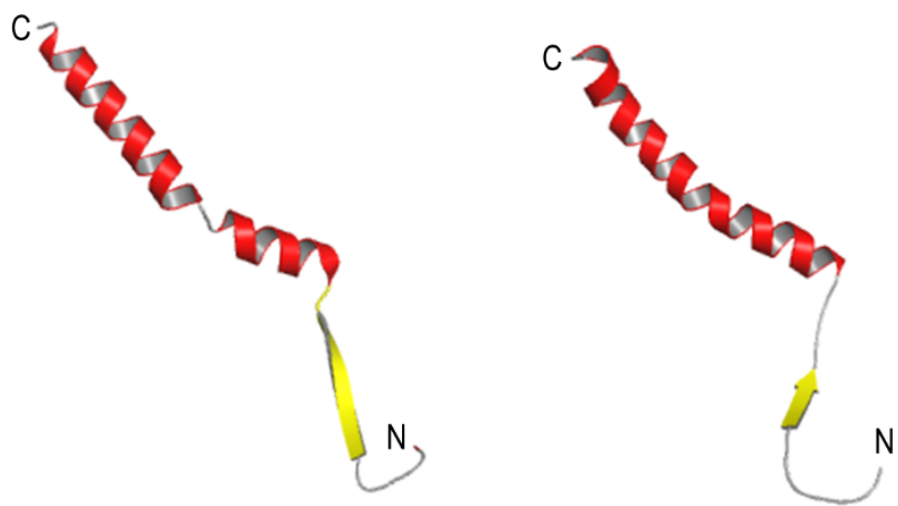
1209 Supplementary Figure S2. Structural analysis of MXAN_7418 (WzpX). (A) Evolutionarily-

1210 coupled amino acids within the MXAN_7418 primary structure (determined via RaptorX). (B) Fold-

1211 recognition analysis of MXAN_7418 (via HHpred) revealing N-terminal structural homology with two

$1212 \beta$-strands from FhuA (PDB: 4CU4) (Mathavan et al., 2014), with the remainder of the protein

1213 displaying structural homology to $\mathrm{PgaA}_{\beta b}$ (PDB: 4Y25) (Wang et al., 2016). FhuA and PgaA $\beta$ B-

1214 strand (dark blue arrows) structure is depicted as per the respective PDB entries. MXAN_7418

1215 predicted $\beta$-strand (light blue arrows) secondary structure is indicated as per PSIPRED analysis.

1216 Aligned residues have been coloured according to Jalview conservation score (out of 10). Maroon,

1217 10; red, 9; orange, 8; yellow, 7; pink, 6. Scores of 5 or less have been omitted to improve clarity of 1218 the figure. 
bioRxiv preprint doi: https://doi.org/10.1101/2022.02.11.480155; this version posted February 12,2022 . The copyright holder for this preprint (which was not certified by peer review) is the author/funder, who has granted bioRxiv a license to display the preprint in perpetuity. It is made available under aCC-BY-NC 4.0 International license.

\section{SUPPLEMENTARY FIGURE S2}

A)

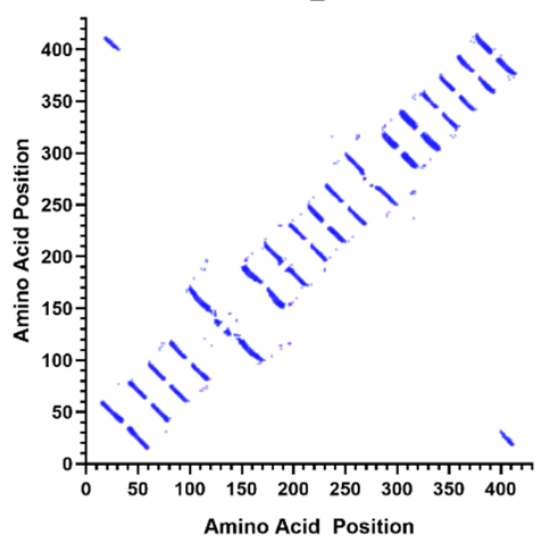

B)
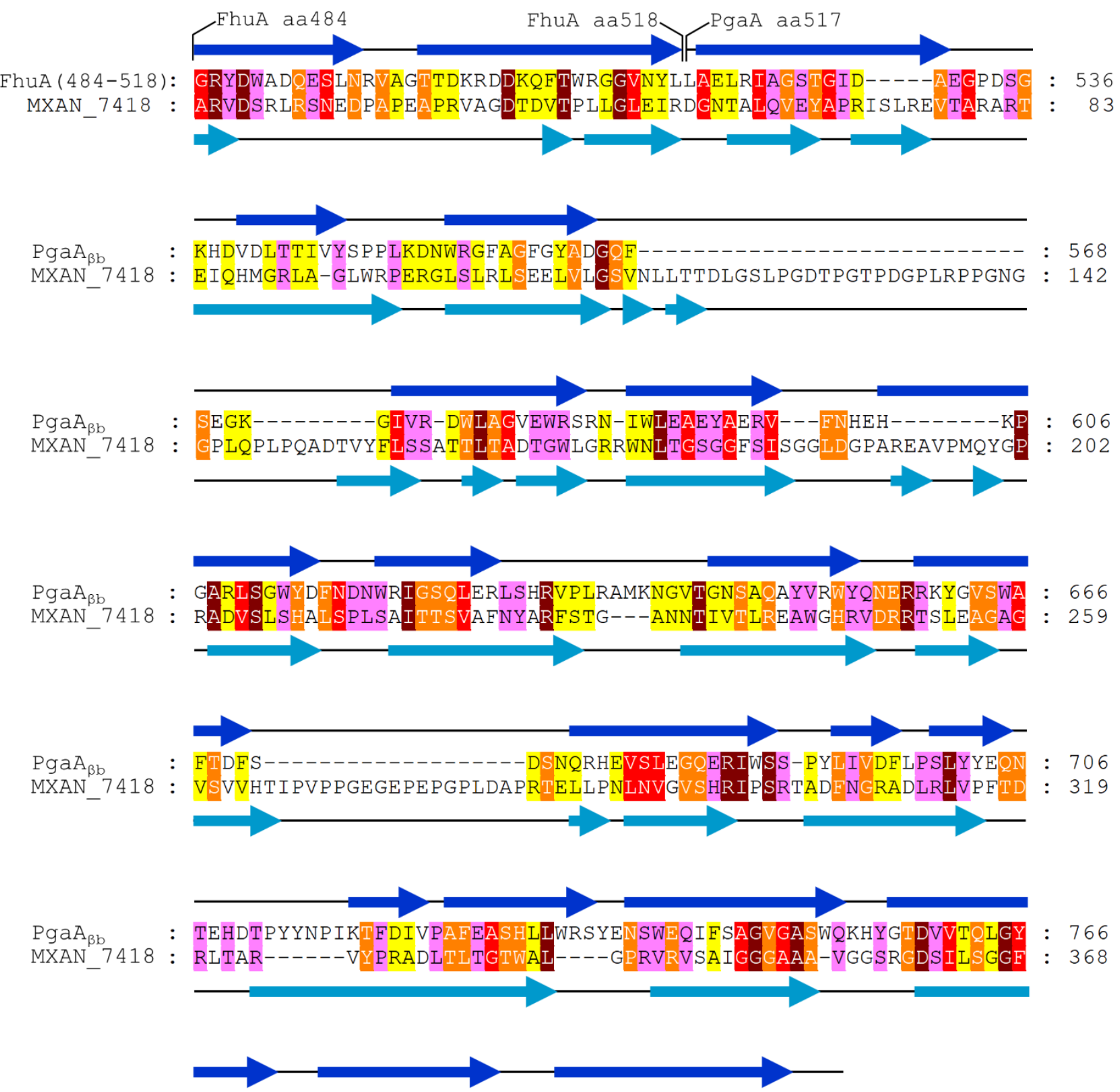

PgaA $_{\beta b}:$ GQRISWNDVIDAGATLRWEKRPYDGDREH--NLYVEFDMTFRE---- : 807

MXAN_7418:TGSWILTRWVSVDIDLRGTWSRSPELPAARLTWAATLGLSVRETGIL : 415 
1220 Supplementary Figure S3. Structural analysis of MXAN_3226 (WzpS). (A) Evolutionarily-

1221 coupled amino acids within the MXAN_3226 primary structure (determined via RaptorX). (B) Fold-

1222 recognition analysis of MXAN_3226 (via HHpred) revealing N-terminal structural homology with two

$1223 \beta$-strands from NanC (PDB: 2WJR) (Wirth et al., 2009), with the remainder of the protein displaying

1224 structural homology to $\mathrm{PgaA}_{\beta b}$ (PDB: 4Y25) (Wang et al., 2016). NanC and PgaA $\mathrm{Ab}_{\beta} \beta$-strand (dark

1225 blue arrows) structure is depicted as per the respective PDB entries. MXAN_3226 predicted $\beta$ -

1226 strand (light blue arrows) secondary structure is indicated as per PSIPRED analysis. Aligned

1227 residues have been coloured according to Jalview conservation score (out of 10). Maroon, 10; red,

12289 ; orange, 8; yellow, 7; pink, 6 . Scores of 5 or less have been omitted to improve clarity of the

1229 figure. 
bioRxiv preprint doi: https://doi.org/10.1101/2022.02.11.480155; this version posted February 12, 2022. The copyright holder for this preprint (which was not certified by peer review) is the author/funder, who has granted bioRxiv a license to display the preprint in perpetuity. It is made available under aCC-BY-NC 4.0 International license.

\section{SUPPLEMENTARY FIGURE S3}

A)

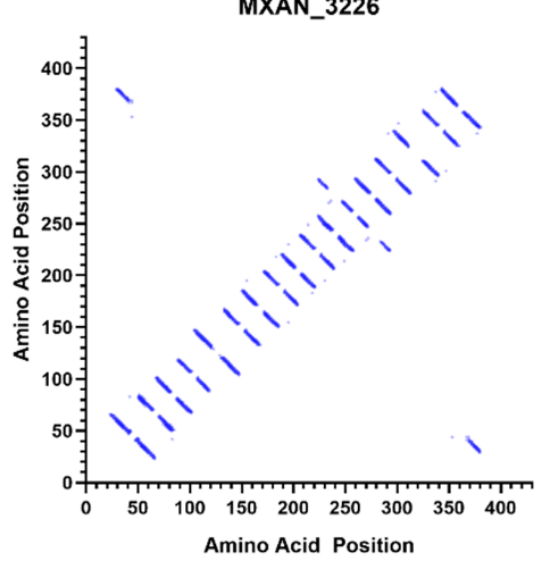

B)

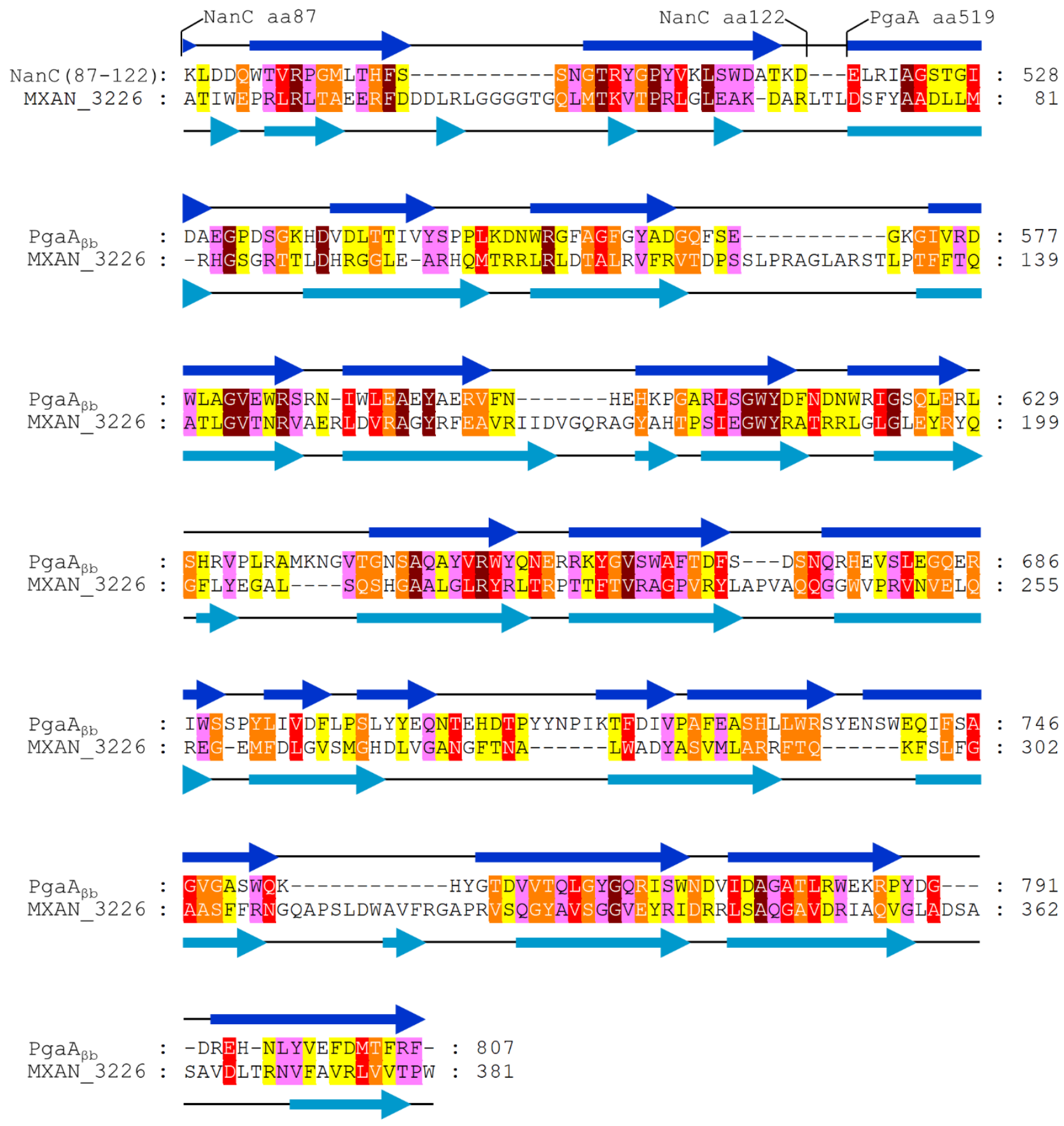




\section{Supplementary Figure S4. Structural analysis of MXAN_1916 (WzpB). (A) Evolutionarily-}

1232 coupled amino acids within the MXAN_1916 primary structure (determined via RaptorX). (B) Fold-

1233 recognition analysis of MXAN_1916 (via HHpred) revealing N-terminal structural homology with two

$1234 \beta$-strands from PagL (PDB: 2ERV) (Rutten et al., 2006), with the remainder of the protein displaying

1235 structural homology to PgaA $_{\beta b}$ (PDB: 4Y25) (Wang et al., 2016). PagL and PgaA $\beta$ B-strand (dark

1236 blue arrows) structure is depicted as per the respective PDB entries. MXAN_1916 predicted $\alpha$-helix

1237 (light green cylinders) and $\beta$-strand (light blue arrows) secondary structure is indicated as per

1238 PSIPRED analysis. Aligned residues have been coloured according to Jalview conservation score

1239 (out of 10). Maroon, 10; red, 9; orange, 8; yellow, 7; pink, 6. Scores of 5 or less have been omitted

1240 to improve clarity of the figure. 
bioRxiv preprint doi: https://doi.org/10.1101/2022.02.11.480155; this version posted February 12, 2022. The copyright holder for this preprint (which was not certified by peer review) is the author/funder, who has granted bioRxiv a license to display the preprint in perpetuity. It is made available under aCC-BY-NC 4.0 International license.

\section{SUPPLEMENTARY FIGURE S4}

A)

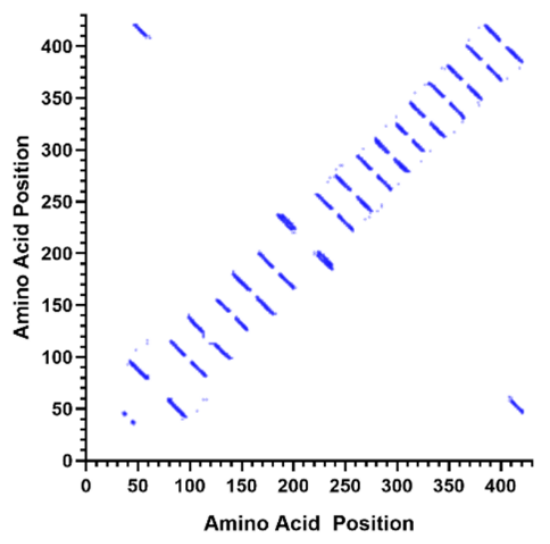

B)

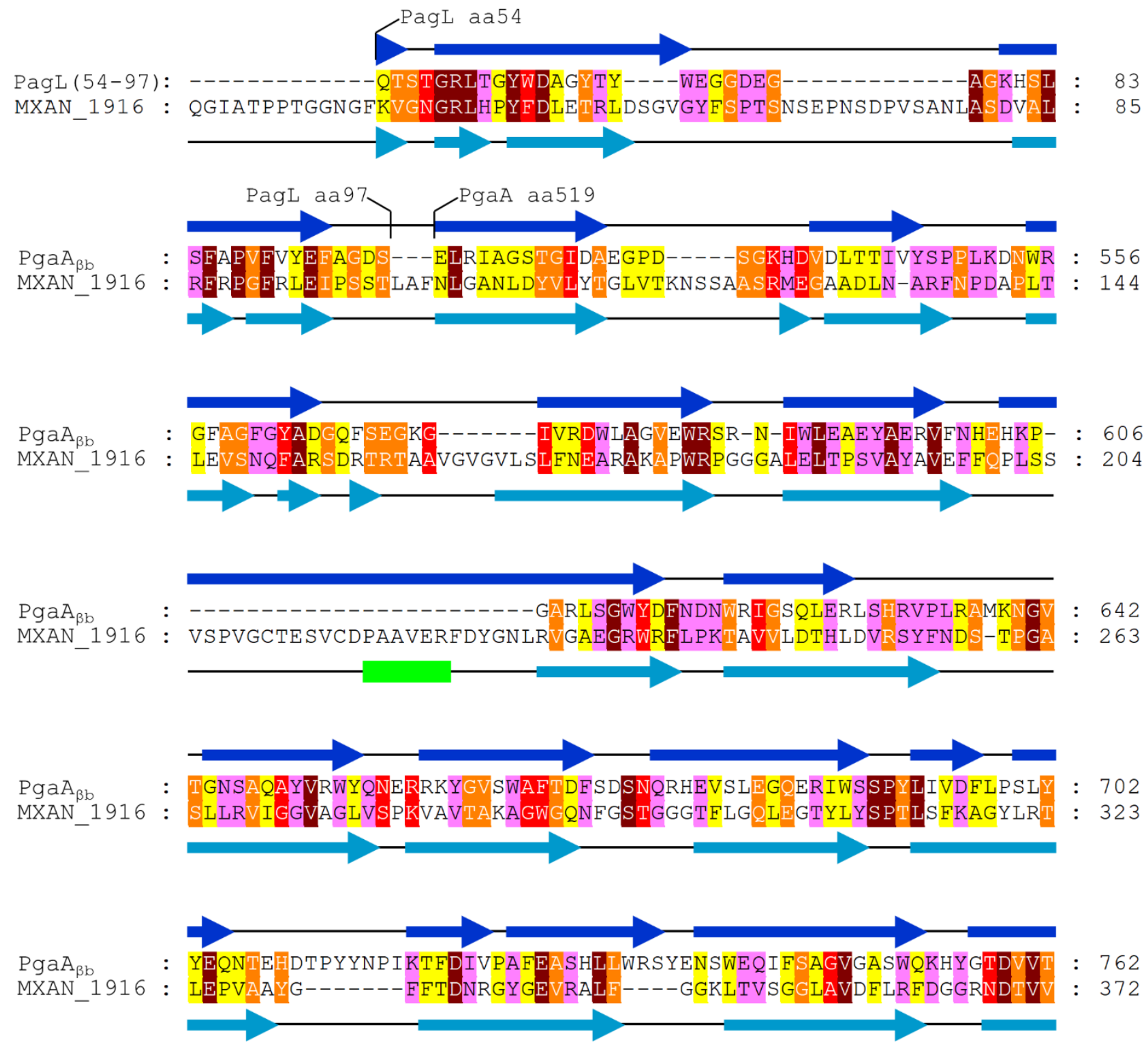

PgaA $_{\beta b}:$ QLGYGQRI SWNDVIDAGATLRWEKRPYDGDR---EH-NLYVEFDMTFRF

MXAN_1916: GVNIGPEYQFYPWLTGAAGYMLGRRSSSVDGGGLNYSRHEGYARLSVTY : 421 


\section{Supplementary Figure S5. Structural homology between Pgaßb, GfcD, and YjbH. (A) Fold-}

1243 recognition analysis of $\mathrm{GfcD}$ and $\mathrm{YjbH}$ (via HHpred) revealing N-terminal structural homology of

1244 each to the amyloid secretion $\beta$-barrel FapF (PDB: 5O65) (Rouse et al., 2017) and C-terminal

1245 structural homology of each to $\mathrm{PgaA}_{\beta b}$ (PDB: 4Y25) (Wang et al., 2016). (B) AlphaFold2-generated

1246 tertiary structure models for GfcD and $\mathrm{YjbH}$, displayed alongside the $\mathrm{Pga}_{\beta \mathrm{b}} \mathrm{X}$-ray crystal structure for

1247 comparison. Proteins have been coloured with a spectrum, from the N-terminus (blue) to the C-

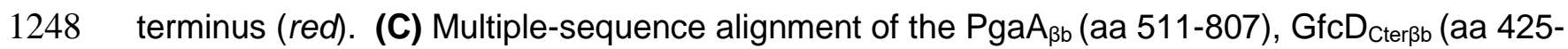

1249 698), and $\mathrm{YjbH}_{\mathrm{Cter} \beta b}$ (aa 423-698) segments. Aligned residues have been coloured according to

1250 Jalview conservation score (out of 10). Maroon, 10; red, 9; orange, 8; yellow, 7; pink, 6 . Scores of 5

1251 or less have been omitted to improve clarity of the figure. 
bioRxiv preprint doi: https://doi.org/10.1101/2022.02.11.480155; this version posted February 12, 2022. The copyright holder for this preprint (which was not certified by peer review) is the author/funder, who has granted bioRxiv a license to display the preprint in perpetuity. It is made available under aCC-BY-NC 4.0 International license.

\section{SUPPLEMENTARY FIGURE S5}

A)

GfcD

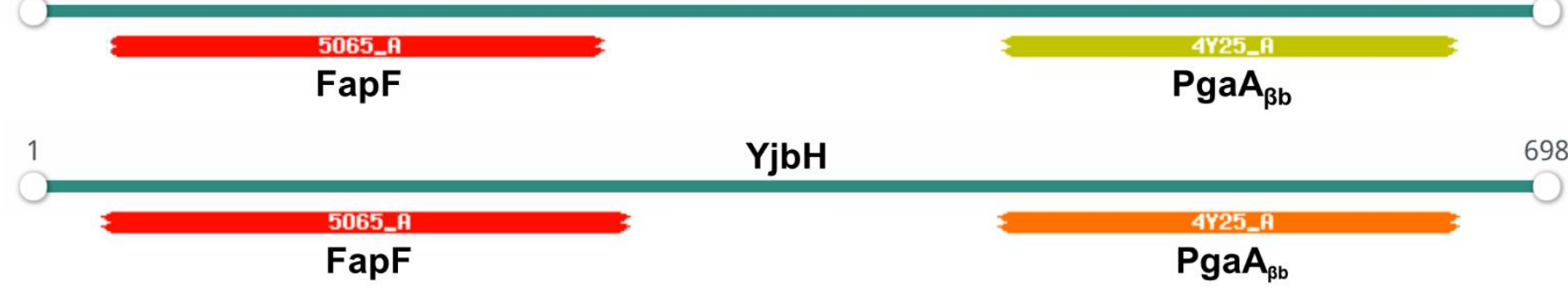

B)

$\mathrm{PgaA}_{\beta \mathrm{b}}$ PDB: 4 Y 25
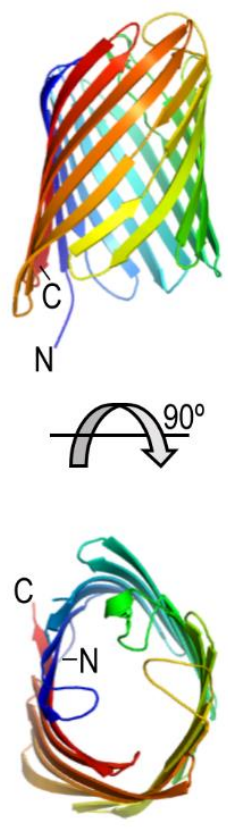

GfcD

UniProt: P75882
YjbH

UniProt: P32689

\section{8}
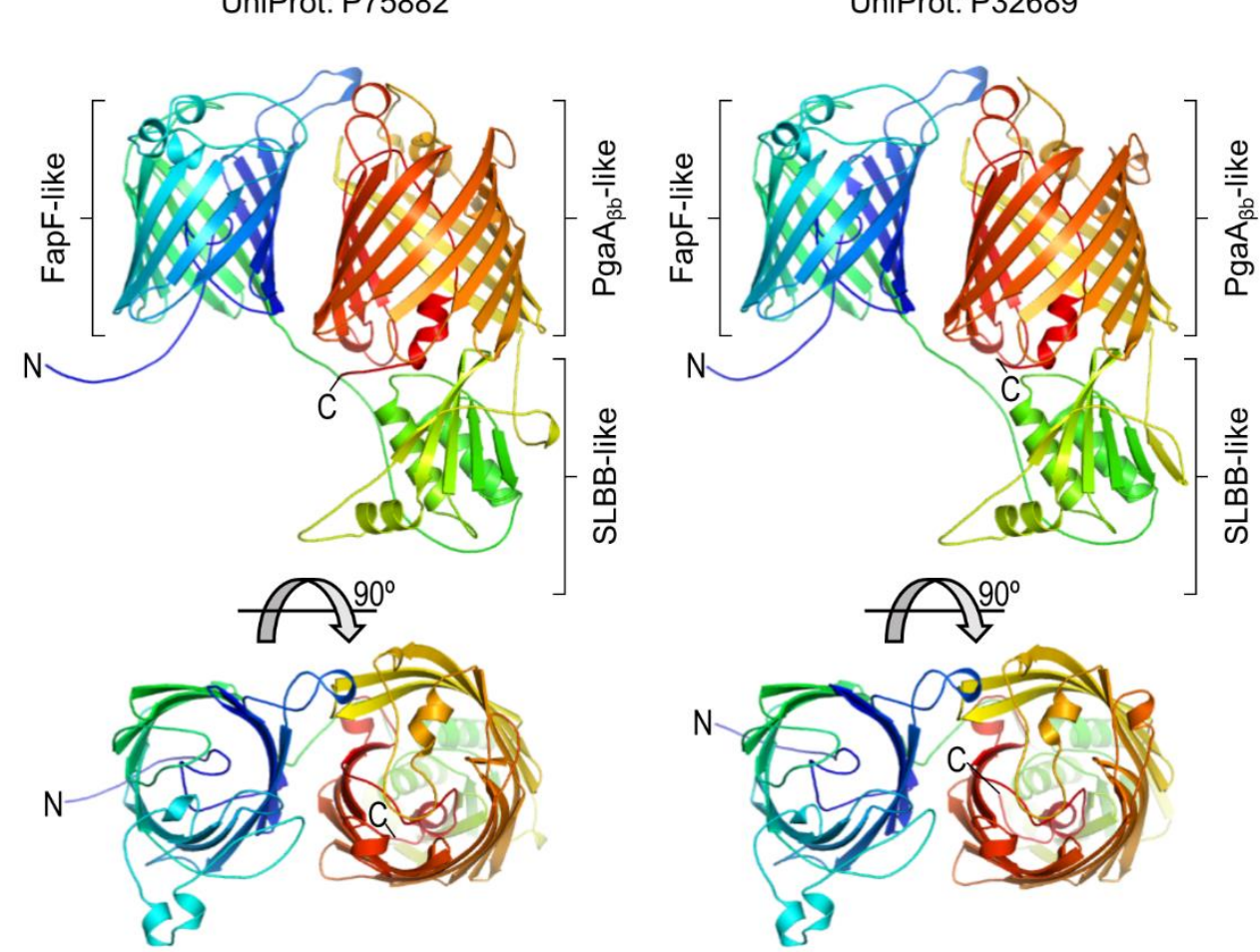

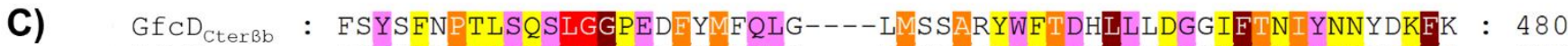

$\mathrm{YjbH}_{\text {Cter } \beta b}:$ FDFHIDPVLNQSVGGPENFYMYQLG----VMGTADLWLTDHLLTTGSLFANLANNYDKEN : 478

$\operatorname{PgaA}_{\beta b}:$-AVDVHNLAELRIAGSTGIDAEGPDSGKHDVDLITIVYSPPLKDNWRGFAGFGADGQES : 569

GfCD $_{\text {CterBb }}$ : SSLLPADSTLPRVRTHIRDYVRNDVYLNNLQANYFADLG--NGFYGQVYGGYLETMYAGV : 538

$\mathrm{YjbH}_{\text {CterBb }}$ : YTNPPQDSHLPRVRTHVREYVQNDVYVNNLQANYFQHLG--NGFYGQVYGGYLETMFGGA : 536

PgaA $_{\beta b} \quad:$ EGKGIVRDWLAGVEWRSRNIWLEAEYAERVFNHEHKPGARLSGWYDFNDNWRIGSOLERL : 629

GfCD $_{\text {Cterbb }}$ : GSELLYRPLDACWALGVDVNYVK--QRDWD---NMMRFTDYS--------TPTGFVTAYW : 585

$\mathrm{YjbH}_{\text {CterBb }}$ : GAEVLYRPLDSNWAFGLDANYVK--QRDWRSAKDMMKFTDYS--------VKTGHLTAYW : 586

PgaA $_{\beta b} \quad:$ SHRVPLRAMKNGVTGNSAQAYVRWYQNERRKYGVSWAFTDFSDSNQRHEVSLEGQERIWS : 689

GfCD $_{\text {Cterßb }}:$ NPPTLNGVLMKLSVGQYLAKDKG-----ATIDVAKRFDSGVAVGVWAAISNVSKDDYGEG : 640

$\mathrm{YjbH}_{\text {Cter Bb }}$ : TPSFAQDVLVKASVGQYLAGDKG-----GTLEIAKRFDSGVVVGGYATITNVSKEEYGEG: 641

$\operatorname{PgaA}_{\beta b}:$ SPYLIVDFLPSLYYEQNTEHDTPYYNPIKTFDIVPAFEASHLLWRSYENSWEQIFSAGVG : 749

GfCD $_{\text {CterBb }}:$ GFSKGFYISIPFDLMTIGPNRNRAVVSWTPLTRDGGQMLSRKYQLYPMTAEREVPVGQ : 698

$\mathrm{YjbH}_{\text {Cterßb }}$ : DFTKGVYVSVPLDLFSSGPTRSRAAIGWTPLTRDGGQQLGRKFQLYDMTSDRSVNFR- : 698

$\operatorname{PgaA}_{\beta b} \quad:$ ASWQKHYGIDVVTQLGYGQRISWNDVIDAGATLRWEKRPYDGDREHNLYVEFDMTFRF : 807 


\section{Supplementary Figure S6. Structural schematic of polymer translocation across the}

1254 periplasm in $\boldsymbol{M}$. xanthus. Components from the BPS secretion pathway have been used as

1255 representative proteins for those in the EPS and MASC pathways as well. All proteins, spaces, and

1256 distances have been depicted at the same relative scale across a representative $327 \AA$ periplasmic

1257 space in a $M$. xanthus cell. X-ray crystal structures for Wza $E_{E c}$ (chain A) and Wzc $E_{E c}$ (chains $F$ and $G$ )

1258 have been provided as per the PDB files 2J58 (Dong et al., 2006) and 7NII (Yang et al., 2021)

1259 (respectively) for size references. Structure models for WzaB (Fig. 1B) and WzpB (Fig. 5A) were

1260 already generated in this investigation. Models for the PCP protein WzcB were generated using

1261 either AlphaFold2 (resulting in an extended conformation), or MODELLER (specifically against the

1262 7NII_F template, resulting in a compact conformation). High-confidence co-evolving amino acids

1263 between WzcB and WzaB have been highlighted with green (86\% probability) and cyan (81\%

1264 probability) spheres. 
bioRxiv preprint doi: https://doi.org/10.1101/2022.02.11.480155; this version posted February 12, 2022. The copyright holder for this preprint (which was not certified by peer review) is the author/funder, who has granted bioRxiv a license to display the preprint in perpetuity. It is made available under aCC-BY-NC 4.0 International license.

\section{SUPPLEMENTARY FIGURE S6}

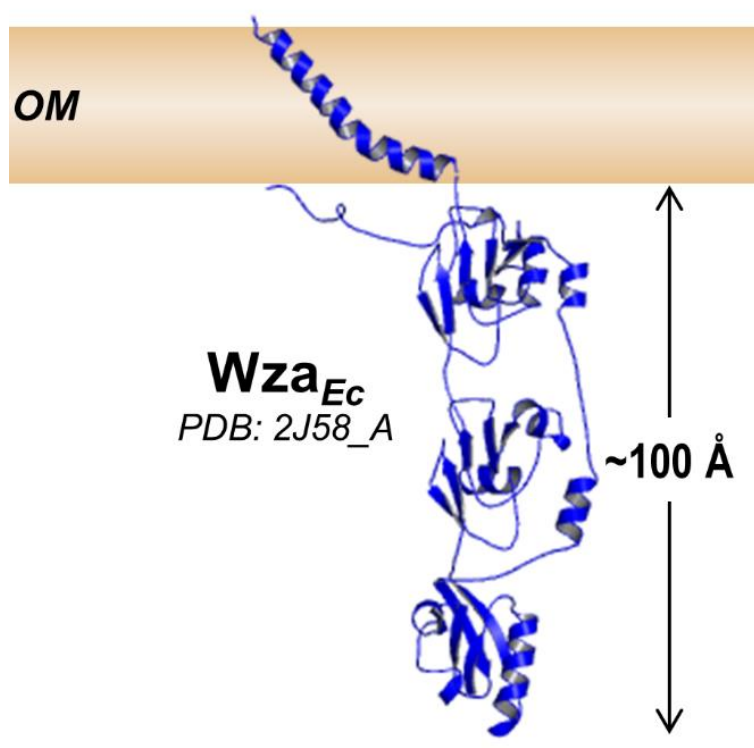

\section{WzpB \\ (MXAN_1916)}

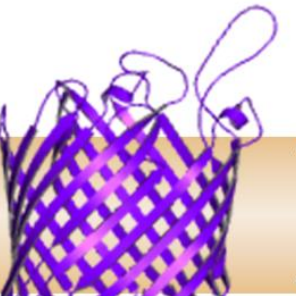

WzaB

(MXAN_1915)

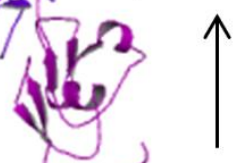

WzaB

(MXAN_1915)

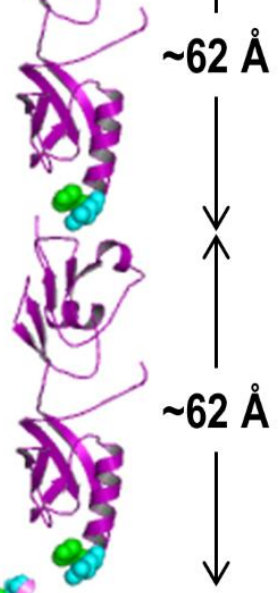

\section{PG}
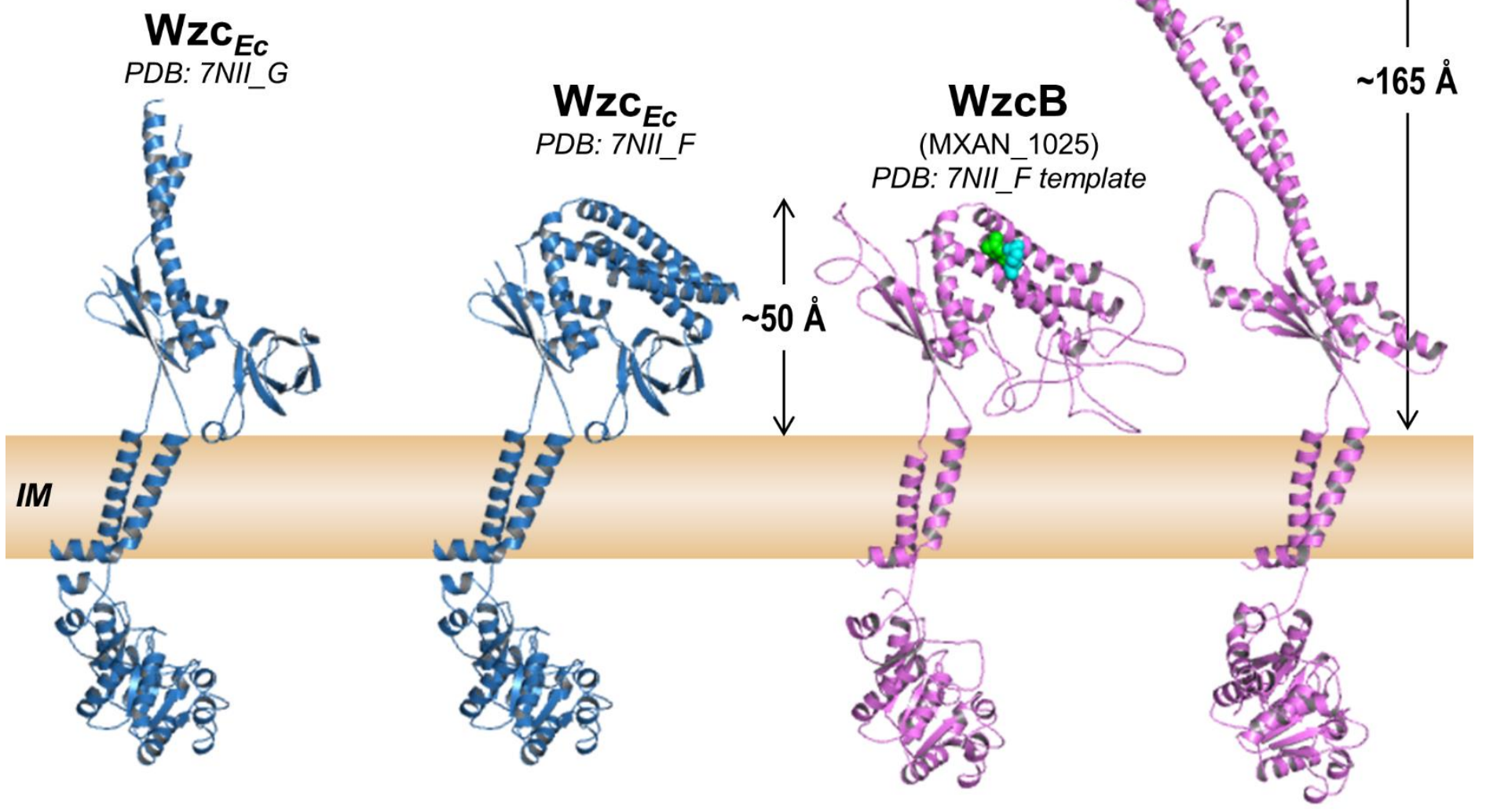


\section{SUPPLEMENTARY TABLE LEGENDS}

1267 Supplementary Table S1. MYXO dataset analysis. (A) Protein-wise OPX classification within 61 1268 myxobacterial genomes. (B) Distribution of OPX-protein types within myxobacterial genomes. (C)

1269 Synteny analysis of OPX-protein types with $\beta$-barrel protein homologues.

1270 Supplementary Table S2. REP dataset analysis. (A) Protein-wise OPX classification within 3662

1271 Representative/Reference genomes. (B) Distribution of OPX-protein Classes within 3662 genomes.

1272 (C) Synteny distribution of OPX-protein types with $\beta$-barrel protein homologues. (D) Arrangement of 1273 syntenic OPX-protein types with $\beta$-barrel protein homologues.

1274 Supplementary Table S3. NR dataset analysis. (A) Protein-wise OPX classification within NR1275 database proteins.

1276 Supplementary Table S4. Distribution of OPX-protein types at Phylum, Class, Order, Family, 1277 and Genus level taxonomy.

1278 Supplementary Table S5. Evolutionary couplings between proteins. Co-evolving amino acids

1279 between PCP and OPX pairs, as well as OPX and Wzp $\beta$-barrel pairs, are presented for constituents 1280 of the EPS, BPS, and MASC pathways. 